\title{
Preprosthetic Surgery
}

\author{
Bobby John
}

The human mandible has no one design for life. Rather it adapts and remodels through the seven stages of life, from the slim arbiter of things to come in the infant, through a powerful dentate machine and even weapon in the full flesh of maturity, to the pencil-thin, porcelain like problem that we struggle to repair in the adversity of old age.

Poswillo

\subsection{History}

The management of discontented denture patients by the act of preprosthetic surgical procedures to enhance the denturebearing areas of the intraoral cavity is a daunting task, which has been performed by the oral and maxillofacial surgeon from time immemorial. Preprosthetic surgery encompasses a distinguished and evolving category of soft and hard tissue procedures.

Pre-prosthetic surgery has emerged from being virtually unknown, passed through a period of opposition and into a state of venerability, and has ultimately made a powerful impact on oral surgery and prosthetic dentistry alike.

A meticulously nurtured and evolved repertoire of ingenious salvage procedures is now alarmingly threatened by a populist 'implants-first' belief that usurps, rather than expands, the traditional prosthodontic treatment spectrum.

Willard [1] is honoured to be the first American dentist to call attention to proper preparation of the mouth for full dentures. Beers [2] in 1876 advocated excision of the alveolus after extraction of teeth, especially if the alveolar process is unusually exhibiting protuberance. Surgery has always been an integral part of the preparation of alveolar ridges for dentures. The last few decades have witnessed an escalating interest in preprosthetic surgery, which has harboured the development of many new techniques.

Electronic Supplementary Material The online version of this chapter (https://doi.org/10.1007/978-981-15-1346-6_17) contains supplementary material, which is available to authorized users.

B. John $(\bowtie)$

Department of Oral and Maxillofacial Surgery, Government Dental College, Kottayam, Kerala, India

\subsection{Pattern of Resorption}

Immediately after extraction, the socket will suffer a reduction in the dimensions both in buccolingual and apicocoronal aspects. This catabolic process can be counteracted by the placement of implants. The resorption of the walls occurs in two phases, which are overlapping in nature. The first phase is characterised by the resorption of bundle bone and replacement with woven bone. The second phase involves the outer surfaces. The exact aetiology for this bone loss is unknown. Roux [3] opined the loss of alveolar bone occurring after tooth loss in the old age is an illustration of disuse atrophy. According to studies by Wolff [4], the mass and structure of the bone can get adapted to the mechanical demands. The resorption is a multifactorial, biomechanical process that results from a combination of anatomic, metabolic, and mechanical determinants. Since all of these factors vary from one patient to the next, these different cofactors may combine in infinite variety of ways, thus explaining the variations in resorption between patients. So ridge resorption is a chronic, progressive, irreversible, and cumulative phenomenon resulting from physiologic, environmental and pathologic components.

Mercier [5] illustrated the general resorptive changes that take place in an edentulous ridge. He summarised the stages as follows:

1. The ridge is wide enough at its crest to accommodate the recently extracted teeth.

2. The ridge becomes thin and pointed.

3. The pointed ridge flattens to the level of the basal bone.

4. The flattened ridge becomes concave as the basal bone resorbs. 
Based on these stages, he grouped the residual ridges as

Group 1-minor ridge remodelling.

Group 2-sharp atrophic residual ridge.

Group 3-basal bone ridge.

Group 4-basal bone resorption.

The pattern of resorption in maxilla differs from that of the mandible. Also, the pattern varies with the site in maxilla and mandible. The extensive study by Cawood and Howell [6] depicts the following conclusions.

Basal bone does not change shape significantly. But if subjected to harmful local effects, it undergoes change.

Alveolar bone exhibits significant changes in shape in both horizontal and vertical axes.

In anterior mandible, the bone loss is vertical and horizontal, but in posterior mandible, the bone loss is mainly vertical.

In anterior maxilla, the bone loss is both vertical and horizontal. The same pattern is exhibited in the posterior maxilla. To summarise, the stage of bone loss varies anteriorly and posteriorly and between the jaws.

\section{Box 17.1 Effects of Edentulism}

- Typical overclosed appearance.

- Neurosensory disturbances.

- Encroachment of muscle tissues leading to instability.

- Prolonged effects of edentulism culminates in pathological fracture.

\section{Box 17.2 Goals of Preprosthetic Surgery}

- Rehabilitation of tissues.

- Relieving of interferences.

- Repositioning of attachments.

- Restoration of alveolar ridge dimensions.

- Re-establishing maxillomandibular relationships in all spatial dimensions.

- Satisfying aesthetics and function.

\subsubsection{Types of Ridges}

Ridges can be classified by their shape. There are V-shaped, U-shaped and knife edged types. The U shaped is the ideal while the V shaped, though successfully distribute the stress but may be unable to retain the peripheral seal during the jaw movements. Knife edged ones are a constant source of soreness under the stress.

A more scientific categorisation is made by Cawood and Howell [6].

Cawood and Howell [6] classification of edentulous jaws:

- Class I-dentate.

- Class II-Immediately post-extraction.

- Class III-well-rounded ridge form, with adequate height and width of the alveolar process.

- Class IV-knife-edge form with adequate height but inadequate width of the alveolar process.

- Class V-flat-ridge form with inadequate height and width.

- Class VI-depressed ridge form with evident basal bone loss.

\subsection{Treatment Planning}

The preliminary step is the assessment of the patient, which commences from the history taking to the physical examination. The role of radiograph is relevant especially the panoramic view to reveal the deep-seated disorders. Storer [7] found $32 \%$ of edentulous patients had an asymptomatic pathologic condition, which warrants the need for radiographic examination. Crandell and Trueblood [8] also advised radiographic examination to rule out the presence of pathologies, root remnants, and even impacted tooth. Radiographic assessment is one of the parameters in detecting bone quality.

Lekholm and Zarb [9] categorise bone quality as follows

Type 1: bone in which almost the entirety is composed of homogeneous compact bone.

Type 2: bone in which a thick layer of compact bone surrounds a core of dense trabecular bone.

Type 3: bone in which a thin layer of cortical bone surrounds a core of dense trabecular bone.

Type 4: bone characterised as a thin layer of cortical bone surrounding a core of low-density trabecular bone of poor strength. 


\section{Box 17.3 Preprosthetic Surgical Procedures can be Classified \\ Ridge correction procedures \\ Hard-tissue correction \\ Alveoloplasty \\ Alveolectomy \\ - Reduction of, Genial tubercles Mylohyoid ridge, Maxillary tuberosity. \\ - Correction of tori, exostoses. \\ Soft-tissue correction \\ - Frenectomy \\ Labial \\ Lingual \\ Excision of hypertrophic tissues}

Ridge extension procedures

Vestibuloplasty

Ridge augmentation procedures

Superior border

Inferior border

Interpositional grafting

Visor osteotomy

Combined with orthognathic surgery

\subsection{Ridge Correction Procedures}

\subsubsection{Alveoloplasty}

The term refers to the restructuring or resurfacing of the alveolar process bone to provide a functional skeletal relationship. Simple plasty insists on the reshaping of the alveolar bone during the extraction procedure. The sharp edges of the alveolus will impede the healing process with symptoms of pain and discomfort. The shape of the ridges with sufficient width and height should be able to distribute the forces properly.

Preservation of alveolar bone is of utmost importance in the extraction procedure. Simple alveolar contouring includes compression and infracture of the socket, but overcompression and reduction should be avoided. If extractions are carried out before the prosthesis fabrication, attempts are made to preserve the alveolus. In multiple extractions, postextraction irregularity exists, which warrants the need for extended alveoloplasty. Here, mucoperiosteal flap may be raised by a crestal incision to get adequate access for the bone reshaping. Extreme care has to be taken during flap elevation since the soft tissues are tightly adhered to the bony irregularities. The use of bone rongeur or file is needed to smooth the edges, but large irregularities may be rectified by rotary instruments. Ensure saline irrigation to keep the temperature below 47 degrees to prevent necrosis. Once the hard tissue is removed, the excess soft tissue is trimmed to prevent the instability of the prosthesis. Closure with absorbable sutures in running or lock stitch fashion is achieved.

\subsubsection{Intercortical Alveoloplasty}

In situations where the alveolar process is prominent but regular, the need for alveoloplasty by the removal of interseptal bone and collapsing the buccal or labial cortical plates to meet the palatal or lingual plates is warranted. This method was propagated by Dean and Mackay [10]. This is an ideal procedure in case of immediate denture placement and usually carried out in the anterior region (Fig. 17.1a and b). This is done by the placement of vertical bone cuts in the canine region through subperiosteal tunnels. Apply the digital pressure to infracture the bone. If unsuccessful, the labial plate can be fractured with an osteotome inserted through a horizontal subperiosteal tunnel made through the vertical lateral incision. The bone distal to the canine is rounded off to maintain the contour. Mucosa is sutured appropriately to retain the new position of the cortices and if needed an acrylic splint may be used to stabilise it.

\subsubsection{Genial Tubercle Reduction}

Genioglossus muscle is one which is adhered to the lingual aspect of the anterior mandible and when the resorption continues, the genial tubercle becomes more prominent and along with the attached muscles creating a displacement of prosthesis. In this case, the pronounced tubercle may be trimmed and released. This procedure may be done alone or in combination with procedures suggestive of lowering the floor of the mouth.

\subsubsection{Procedure}

A crestal incision from the midline to the midbody of mandible is made to get adequate access, followed by dissection in subperiosteal fashion, thus exposing the tubercle and the attached muscle. Muscle may be excised from the bony attachment by using a monoplanar electrocautery with care to be taken to achieve haemostasis or else chance of airway embarrassment by the occurrence of expanding hematoma. The exposed genial tubercle is trimmed by round or fissure bur. Further smoothening is made by bone file. The flap is returned to the original position and closed by nonresorbable 

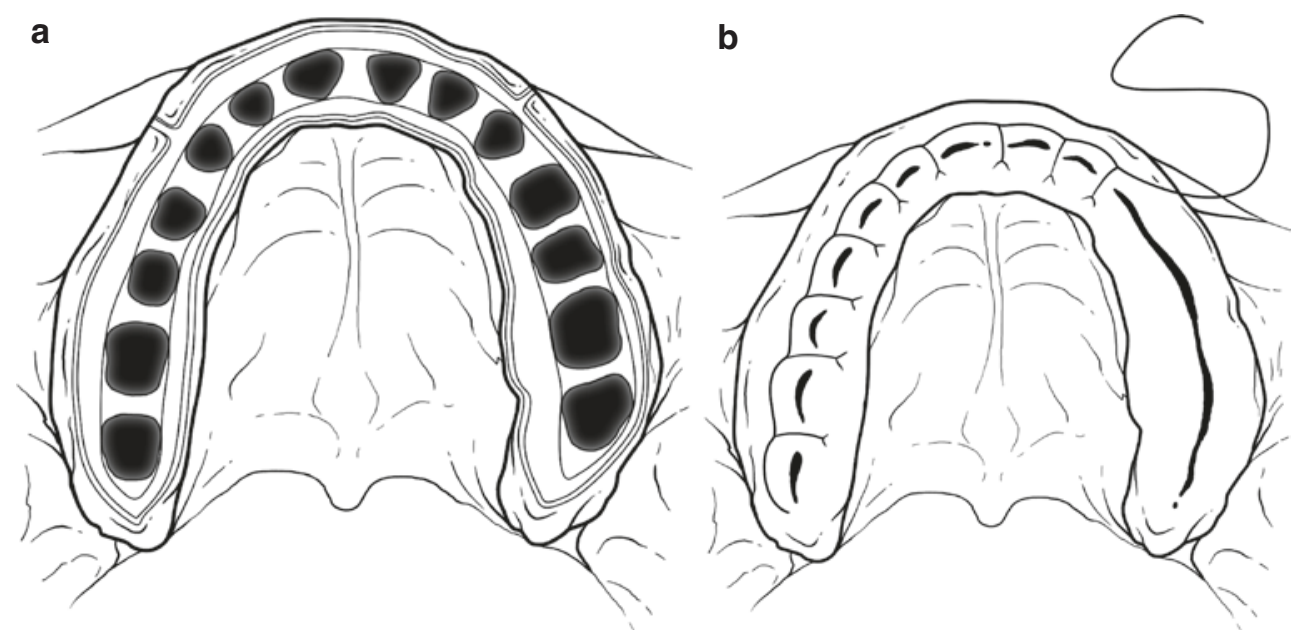

CAssociation of Oral and Maxillofacial Surgeons of India

Fig. 17.1 (a) Incision for intercortical alveoloplasty (b) closure of wound

sutures. Anderson [11] proposed reattaching the genioglosus and geniohyoid muscles at a lower level. Here, he advocated using a sagittal incision in the midline in the periosteum and exposing the genial shelf. The tubercle is reduced and the incision is closed with absorbable sutures.

\subsubsection{Mylohyoid Ridge Reduction}

In cases of extensive resorption, the ridge becomes prominent and creates hurdle for the smooth placement of denture; hence, the need for ridge reduction occurs. The denture flanges impinge on the sharp mylohyoid ridge and patient experiences pain and discomfort. The advent of implants may obviate the need for such a surgical procedure, yet in many cases where implant placement is not feasible, the dentures become a necessity and the mylohyoid ridge reduction needs to be accomplished.

\subsubsection{Procedure}

The procedure can be carried out under local anaesthesia or sedation. After successful nerve block, the incision is carried out along the crest of the ridge in the posterior mandible area followed by subperiosteal dissection and exposure of the mylohyoid ridge and the attached muscle (Fig. 17.2a and b). The muscle is detached and relieved. The residual ridge is smoothed with file, flap returned, and closed with sutures (Fig. 17.2c). Care is ensured to obtain haemostasis.

\subsection{Maxillary Tuberosity Reduction}

Maxillary tuberosity may be enlarged in size and it engorges the intermaxillary space and interferes with denture placement. The reduction of the tuberosity may be needed to create space for the placement of dentures. Generally, the intermaxillary distance should be at least $1 \mathrm{~cm}$ when patients are placed into the correct or planned vertical dimension of occlusion. The excessiveness of the tuberosity and the need for its reduction can be assessed by some clinical manoeuvres. An instrument like a dental mirror can be used to assess the vertical clearance by passing it between the tuberosity and retomolar tissues. The mirror may be positioned in the lateral aspect and the patient is instructed to open and close mouth so as to determine the need for reduction of tuberosity in the horizontal plane. The pneumatisation status should be ascertained before the reduction procedure is undertaken since the maxillary sinus may descend into the tuberosity. So a radiographic examination is essential prior to surgical management. An elliptical incision is made followed by subperiosteal dissection. The engorged tuberosity is trimmed to the desired level and excessive tissue is removed from both buccal and palatal side. The amount of bone removal can be dictated by a surgical guide that was created from study models. Rotary instrumentation, rongeur and a bone file may be used to remove the bone. The flaps are trimmed to leave the excess redundant tissue and sutured in place (Fig. 17.3a-f). Guernsey [12] proposed a different technique for the reduction of the tuberosity. He advised placing a horizontal incision superiorly in the vestibule from the premolar area to the posterior aspect of the tuberosity and a mucoperiosteal flap is released inferiorly to get access to the tuberosity region. Any excessive soft tissue of fibrous nature is removed from within the flap and excessive bone is also removed by using suitable instruments. To correct the redundancy of tissues, soft tissue may be removed from the superior aspect of the incision and flap is sutured back to the periosteum and a stent is placed. This method claims to increase the vestibular depth to some extent (Fig. 17.4a-d). Antral communication should be checked and if present managed accordingly. 


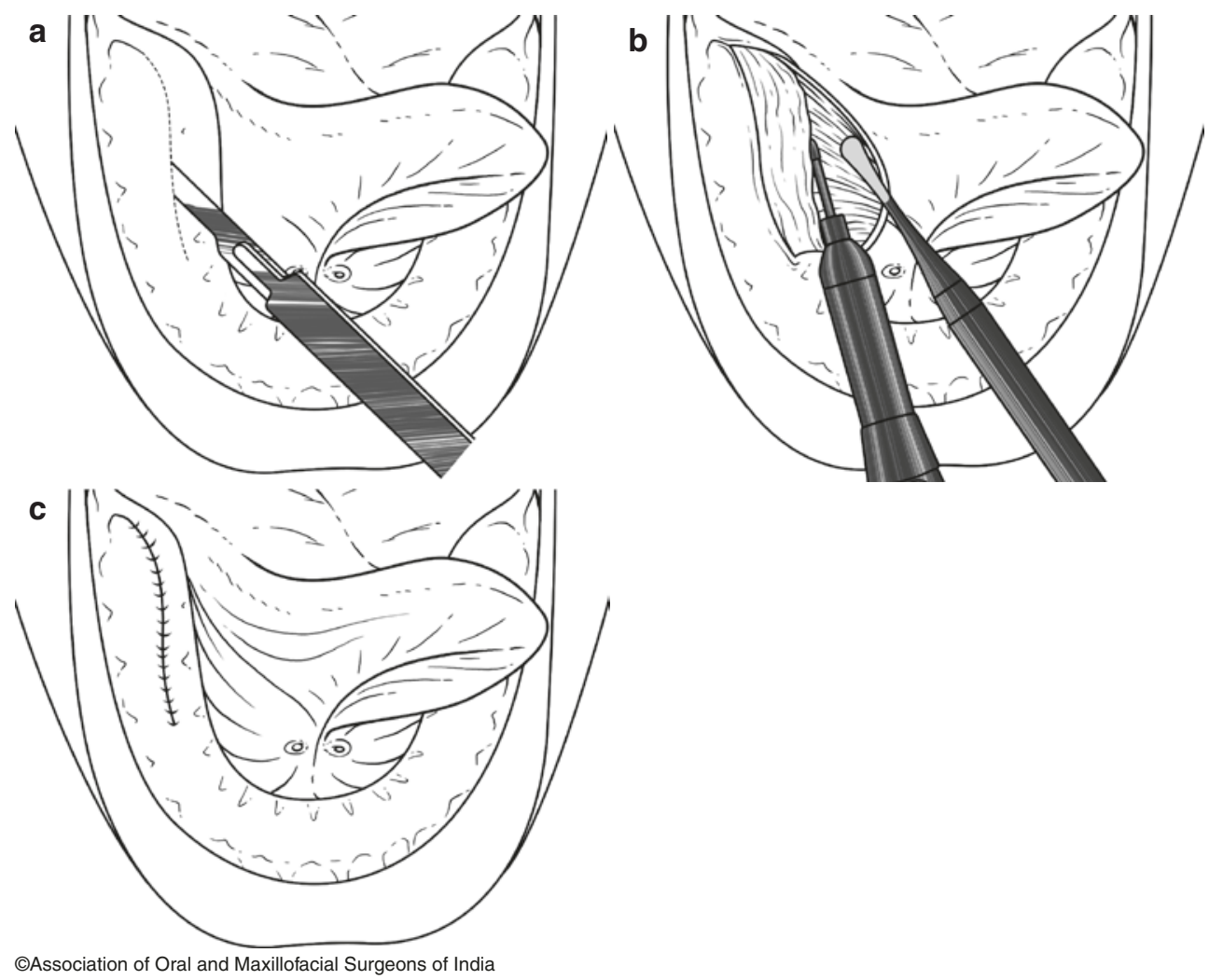

Fig. 17.2 (a) Incision along the crest of the ridge (b) flap raised and bone trimmed (c) sutured the incision

\subsection{Torus Removal}

Tori, meaning 'to stand out' or 'lump in Latin, refer to innocuous bony outgrowths. The aetiology of the occurrence is unclear. Early description of the occurrence of tori is found in the Proceedings of the Royal Society of Medicine by Rickman Godlee [13], which was followed by the reports from various authors and later beautifully summarised by Garcia Garcia [14]. In dentate individuals, the removal of torus may not be needed unless it impedes with functions or it generates discomfort. But in edentulous, the presence of tori precludes the smooth placement of denture, so the removal becomes mandatory. Other indications include mucosal surface getting traumatised with frequent episodes of ulceration, presenting with deep undercuts and multiple nodules and psychological issues. Literature also suggests tori as donor sources of autogenous bone for intraoral grafting procedures. Morraes et al. [15] and Hassan et al. [16] describe the versatility of the grafts from torus for reconstructive methods.

Classification of tori was initially proposed by Kolas [17], who classified them according to number of nodes and their placement as bilateral single, bilateral multiple, unilateral single, and unilateral multiple [18].

Haugen [19] formulated the categorisation of torus based on the size. It is illustrated as.

Type A-small tori into less than $2 \mathrm{~mm}$ in their largest diameter.

Type B-medium-2-4 $\mathrm{mm}$ in their largest diameter.

Type $\mathrm{C}$-large- and more than $4 \mathrm{~mm}$ in their largest diameter.

Reichart [20] in his modification of Haugen's classification suggested few changes:

Grade I-Tori up to $3 \mathrm{~mm}$ in their largest dimension, Grade II-Tori up to $6 \mathrm{~mm}$ in their largest dimension and.

Grade III-Tori above $6 \mathrm{~mm}$ belong to this group. 

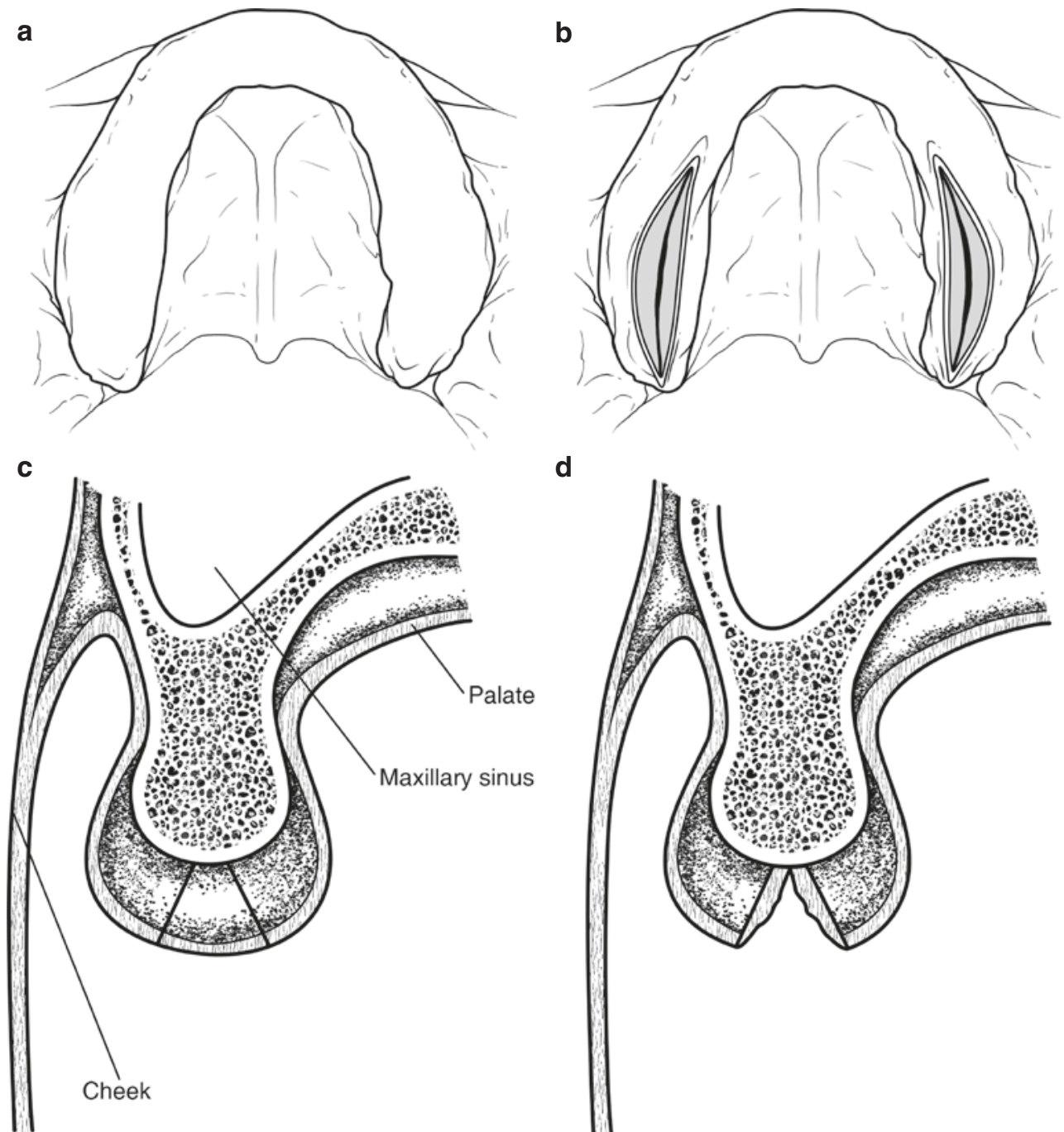

d
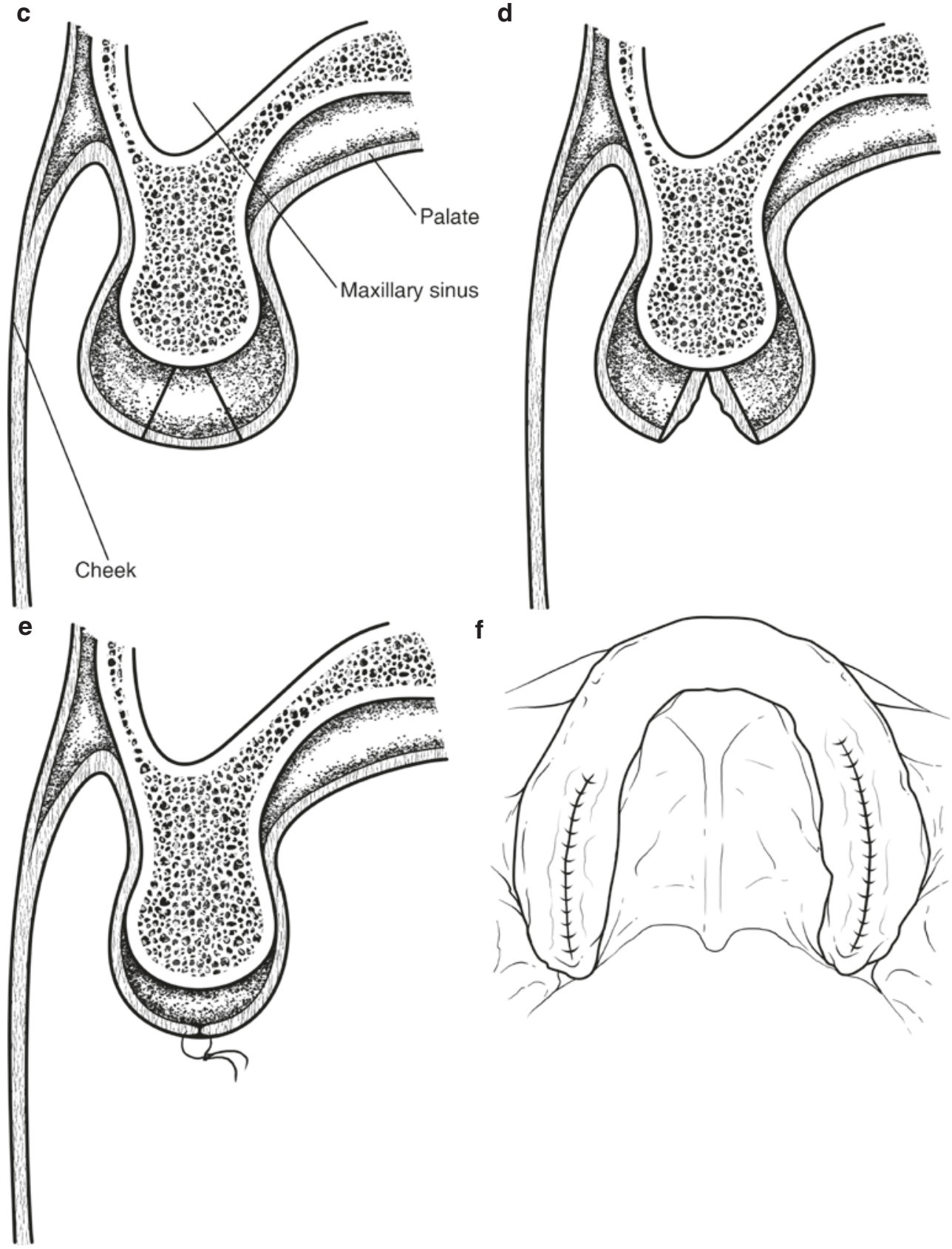

(c)Association of Oral and Maxillofacial Surgeons of India

Fig. 17.3 (a) Bulbous tuberosity, (b) incision placed and flap raised (c and $\mathbf{d})$ reduction, (e and $\mathbf{f})$ sutured incision 

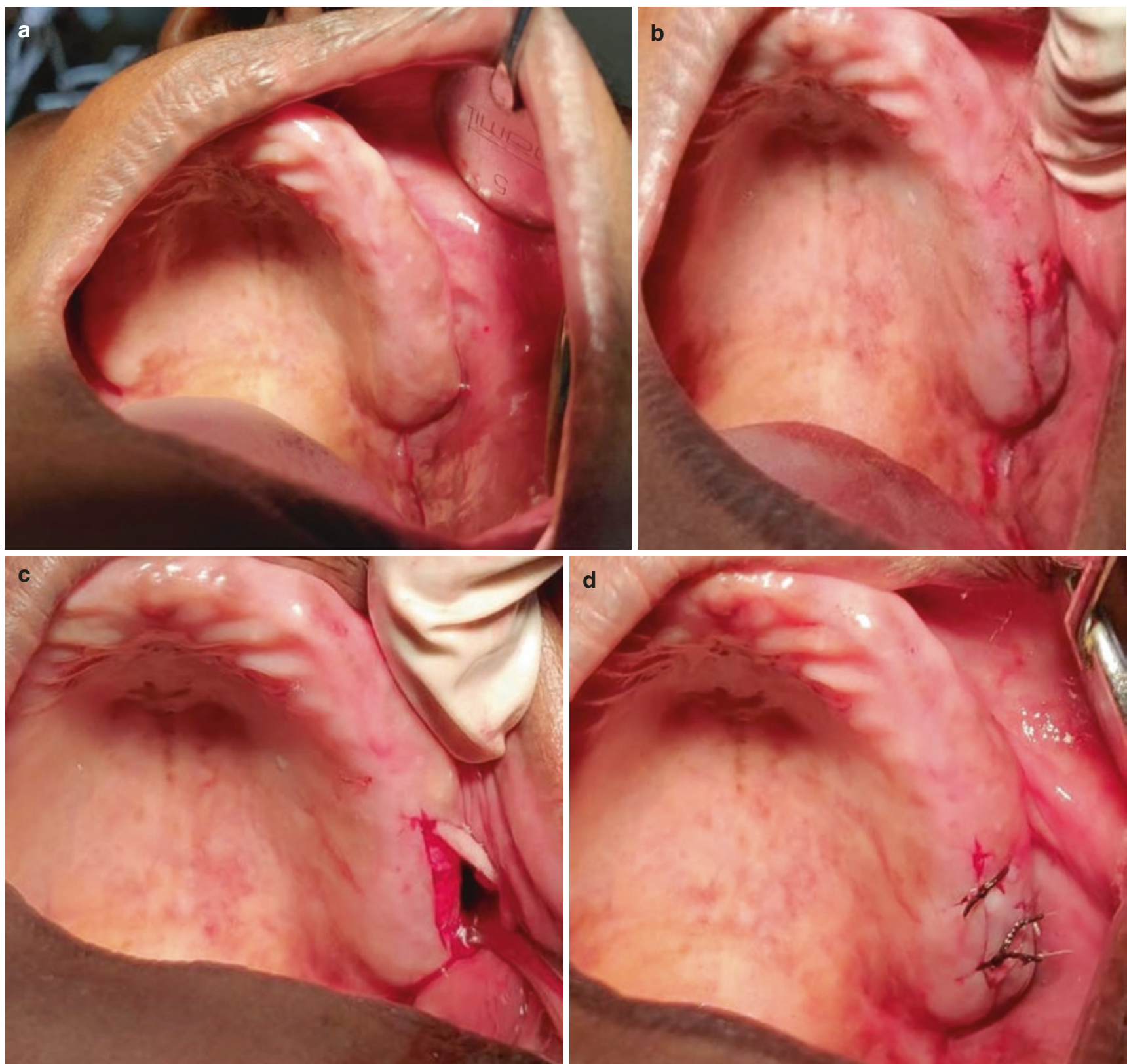

CAssociation of Oral and Maxillofacial Surgeons of India

Fig. 17.4 Clinical photograph showing (a) bulbous tuberosity (b) incision (c) flap reflection (d) sutured wound

\subsubsection{Palatal Tori Removal}

As in any surgical procedures, here also the general systemic condition of the patient may be ascertained and the patient should be warned of the potential complications like the perforations leading to oronasal communication and wound dehiscence. To overcome this problem, preoperatively an impression may be made and cast is fabricated and splint is prepared. Palatal tori may be of different shapes, like lobulated or nodular. The morphology of the torus dictates the incisions required to expose it. Surgical access is accomplished by various types of incisions, "C-" or "U-" shaped incision, palatal incision or double " $Y$ " incision also known as open-door technique. Most commonly used is double Y incision (Fig. 17.5a-f). After successful anaesthesia, a midline incision in anteroposterior direction is made from a few 

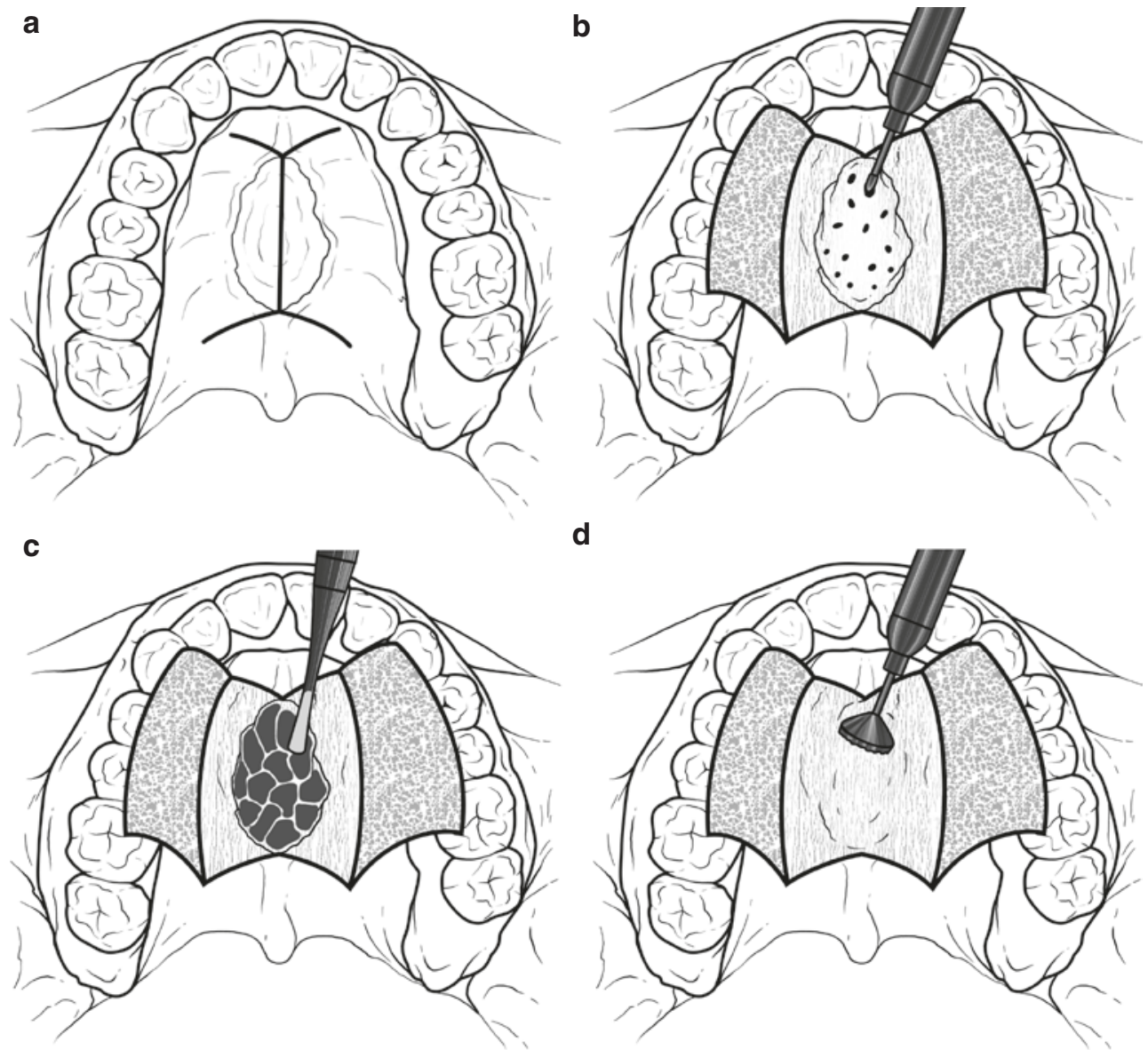

d
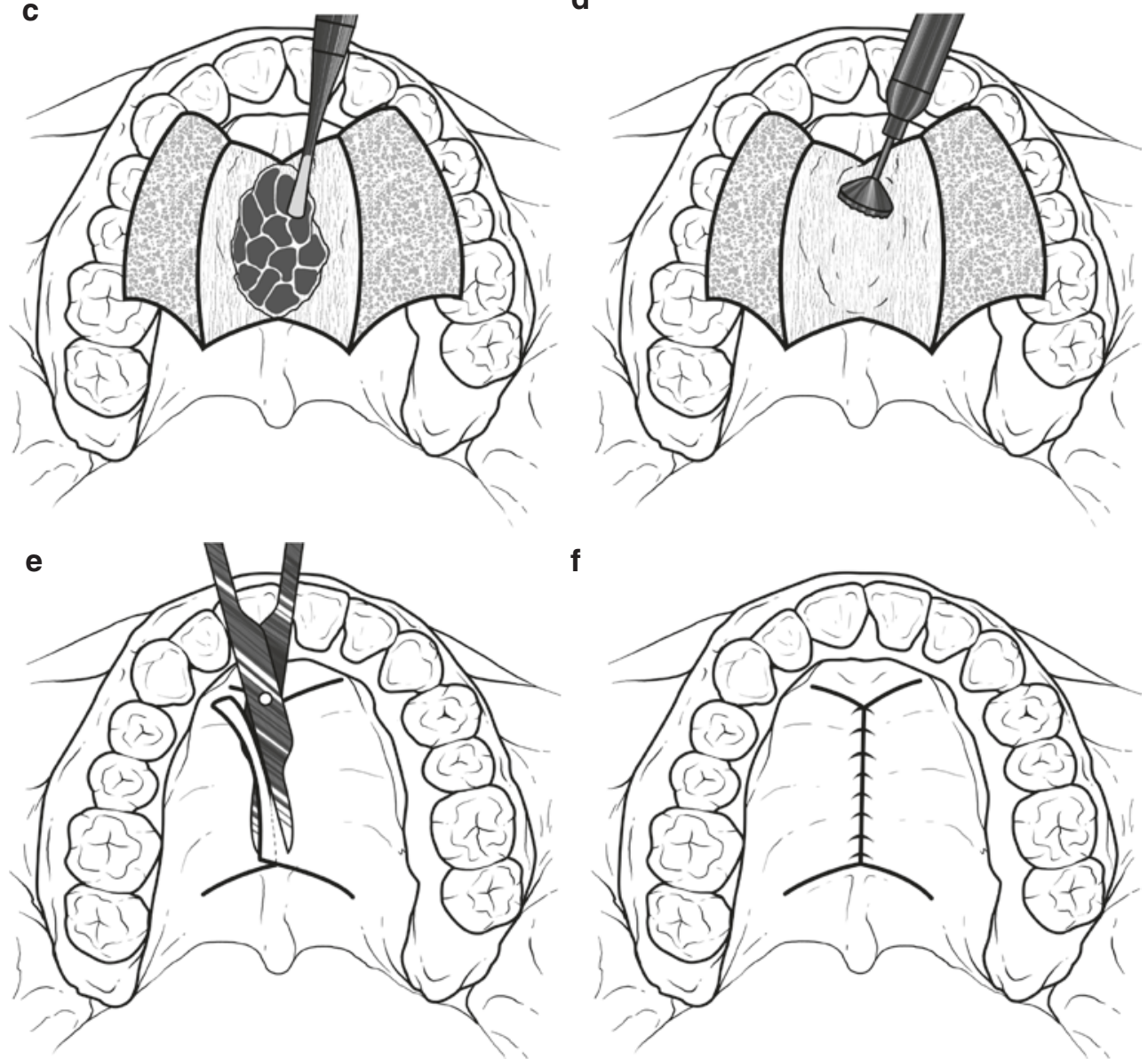

f

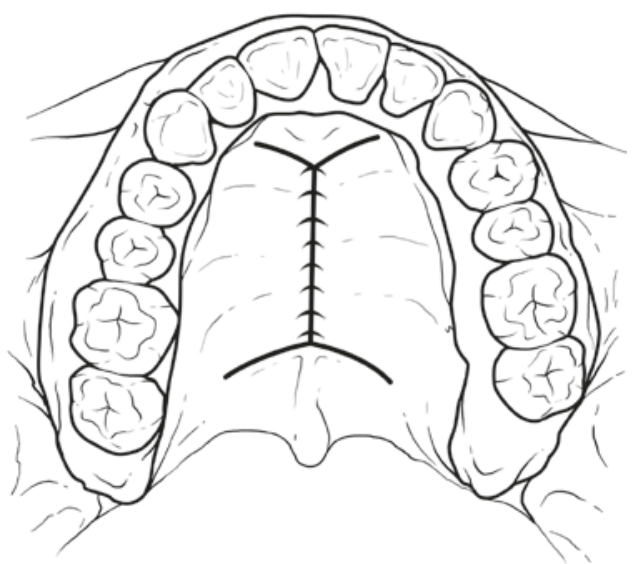

CAssociation of Oral and Maxillofacial Surgeons of India

Fig. 17.5 (a) Incision, (b) flap raised, (c) multiple grooves made, (d) final trimming by acrylic trimmer, (e) excess soft tissue trimmed, (f) closure

$\mathrm{mm}$ ahead of the anterior margin of the torus and continued posteriorly to the most posterior visible point of the torus. Oblique-releasing incisions may be placed at the anterior end of the midline incision and may be extended laterally and anteriorly to end lateral to the lateral margins of the torus. From the posterior end of the midline incision without violating the soft palate, posterior releasing incisions may be placed to extend obliquely in a lateral and posterior direction. Thus, a fair access is obtained. The subperiosteal flap is raised. The small torus can be easily removed by round. But in case of large ones, grooves are created and separated into discrete segments with bur and then by osteotome (Fig. 17.6). 


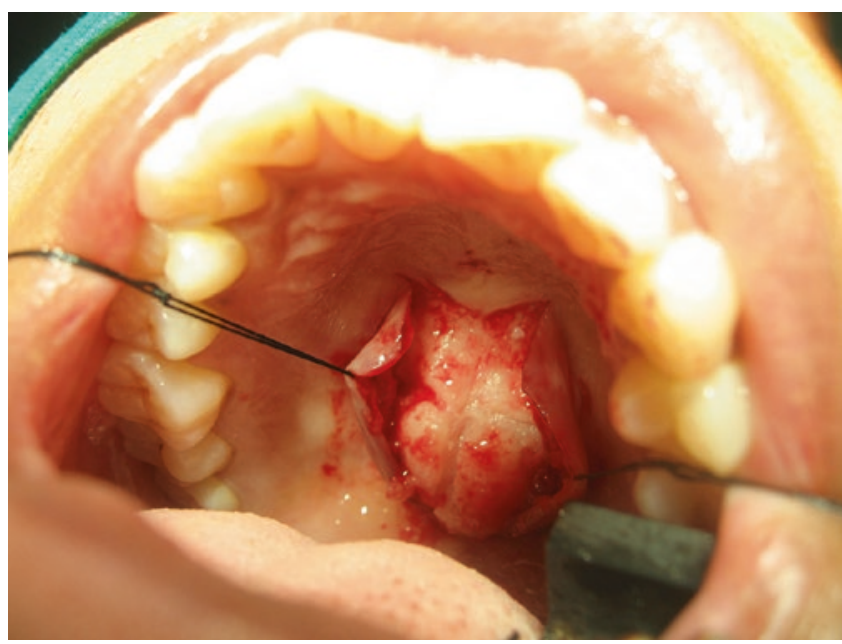

CAssociation of Oral and Maxillofacial Surgeons of India

Fig. 17.6 Clinical photograph showing palatal tori and surgical exposure, double Y-incision used

Copious irrigation is done to clear the debris and flap repositioned in primary fashion. The fabricated stent may be placed to avoid the haematoma and the dead space formation.

\subsubsection{Lingual Torus}

The lingual tori are found in the lingual aspect of the alveolar ridge in the canine and premolar regions. They vary in size and shape; some are pedicled, while others are broad based. An intrasulcular incision without releasing is made from the lingual midline to a point beyond the posterior limit of the tori. In edentulous case, the incision may be placed in the crest of the alveolar ridge. A full-thickness flap is raised to expose the tori and if needed local anaesthetic may be injected in the area to balloon the tissues for easy elevation of the flap. The vertical-releasing incision should be avoided to prevent the vascularity compromise.

The lingual torus may be removed by bur or osteotome. Smaller ones can be easily removed by bur, but the larger require cleavage plane created by bur and later completed by osteotomes. After the removal of the tori, it is essential to check the surface and clear of the irregularities by the use of rongeur and bone files. The flap repositioned and sutured.

\subsection{Exostosis}

It is a benign osseous hypertrophic formation with more predilections to the maxilla. A mucoperiosteal flap is elevated after adequate infiltration of the mucosa. The bone is resected and smoothed with an osteotome or a bur. The smooth placement of the prosthesis is achieved by the facilitation of the errorless foundation, constituted by both hard and soft tissues. In many cases, the hard-tissue framework may be normal, but the soft-tissue impediments affect the stability of the prosthesis. So, the correction of the interferences by the abnormal soft tissues is needed.

Apart from hard tissues, sometimes soft-tissue interferences inhibit the smooth placement of the prosthesis. The unfavourable soft-tissue framework affects the stability of the prosthesis and needs correction by various procedures.

\subsection{Excision of Reactive Inflammatory Papillary Hyperplasia}

This is commonly associated with prolonged wearing of an ill-fitting denture. The condition is recognised as reddened, nodular, or papillary excrescences arising from the palatal mucosa. It can be seen in areas where the denture flanges rest. Removal is accomplished by local anaesthesia or sedation (Fig. 17.7).

\subsection{Frenectomy}

Active and strong frenal attachments interfere with the placement of dentures and the relief of attachments are needed. Various incisions like v-y, z plasty, and diamond-shaped incisions are used in frenectomy procedures.

\subsubsection{Labial Frenectomy (Video 17.1)}

In the edentulous state, the abnormal frenal attachment gets irritated by the denture flanges leading to instability. The denture area can be relieved but it may be unaesthetic, so the need for frenectomy arises. $Z$ plasty is used to eliminate the abnormal attachment. Another method is the V- Y procedure but has a disadvantage of creating excessive bulk of tissue at the depth of vestibule. The operative procedure is as follows (Fig. 17.8a, b and c). It is carried under local anaesthesia, but the tissue should not be overdistended. The lip is extended and everted to tense the frenum. The V-shaped piece of tissue is held by tissue forceps or Allis clamp, and an incision is made down to the periosteum on either side of the frenum. Resorbable sutures are preferred since the removal is difficult in this area. The first suture should be placed at the depth of the vestibule and should engage the periosteum to prevent the loss of the vestibular depth (Fig. 17.9a-e). 

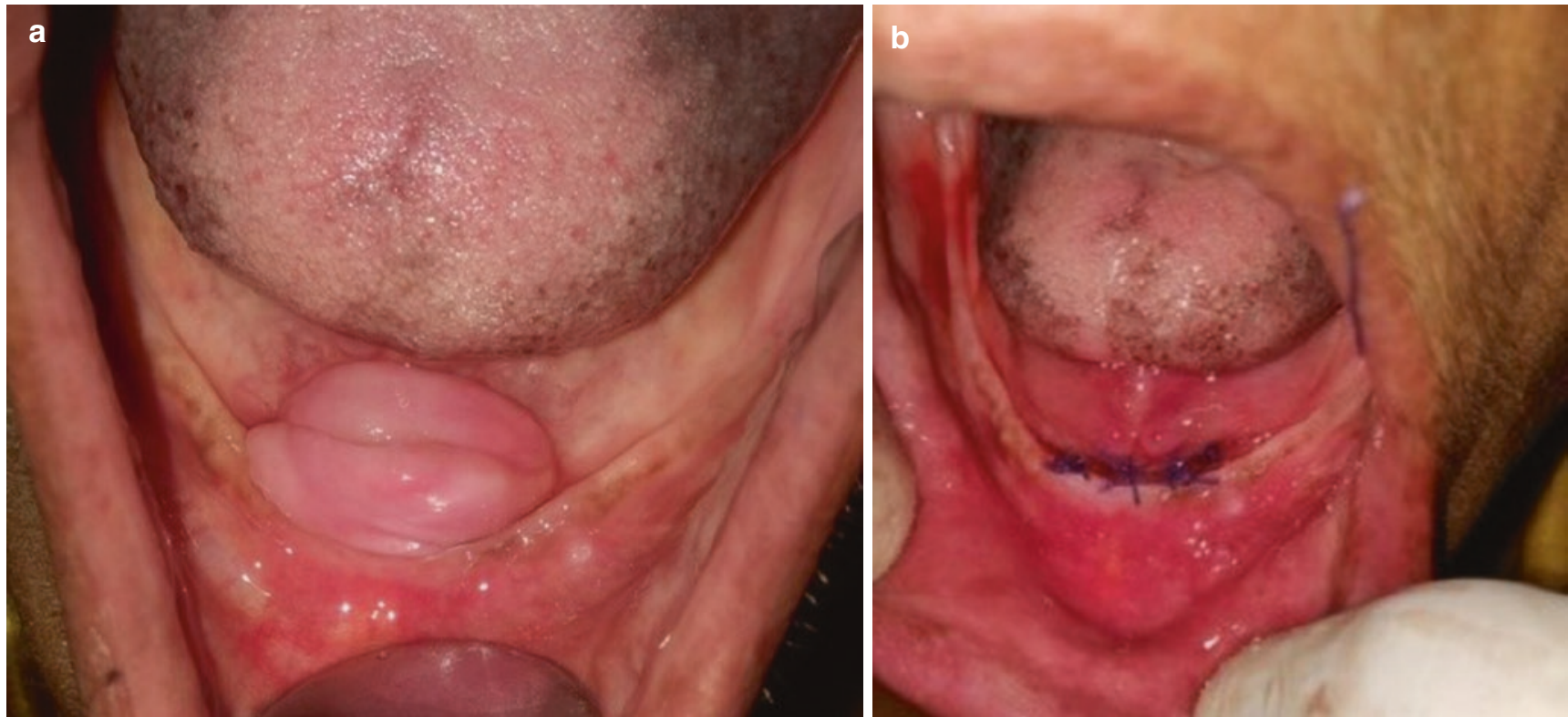

CAssociation of Oral and Maxillofacial Surgeons of India

Fig. 17.7 Clinical photographs showing (a) lingual papillary hyperplasia (b) suturing after excision
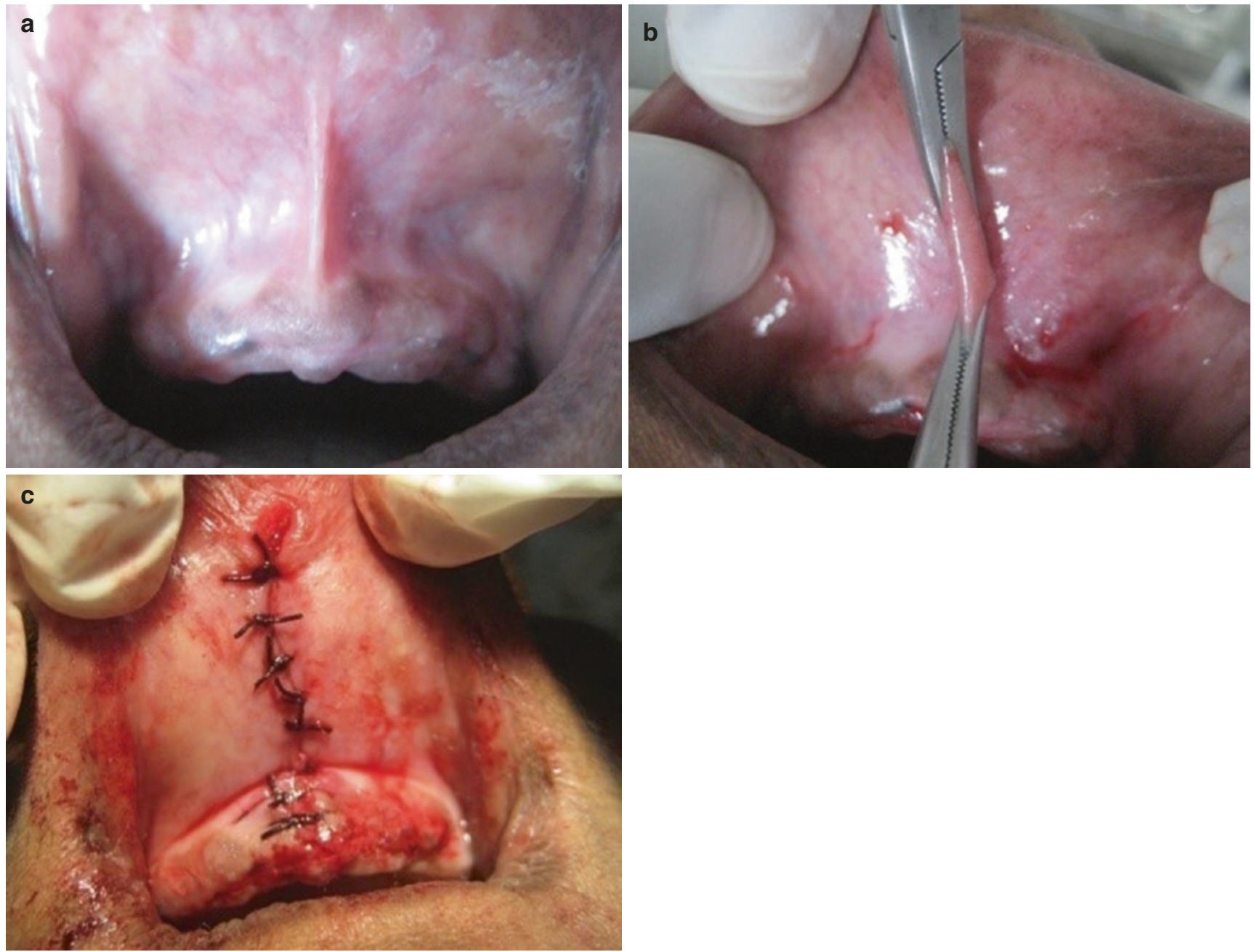

CAssociation of Oral and Maxillofacial Surgeons of India

Fig. 17.8 Clinical photographs showing (a) abnormal attachment of frenum (b) tissue held with mosquito forceps (c) suturing 

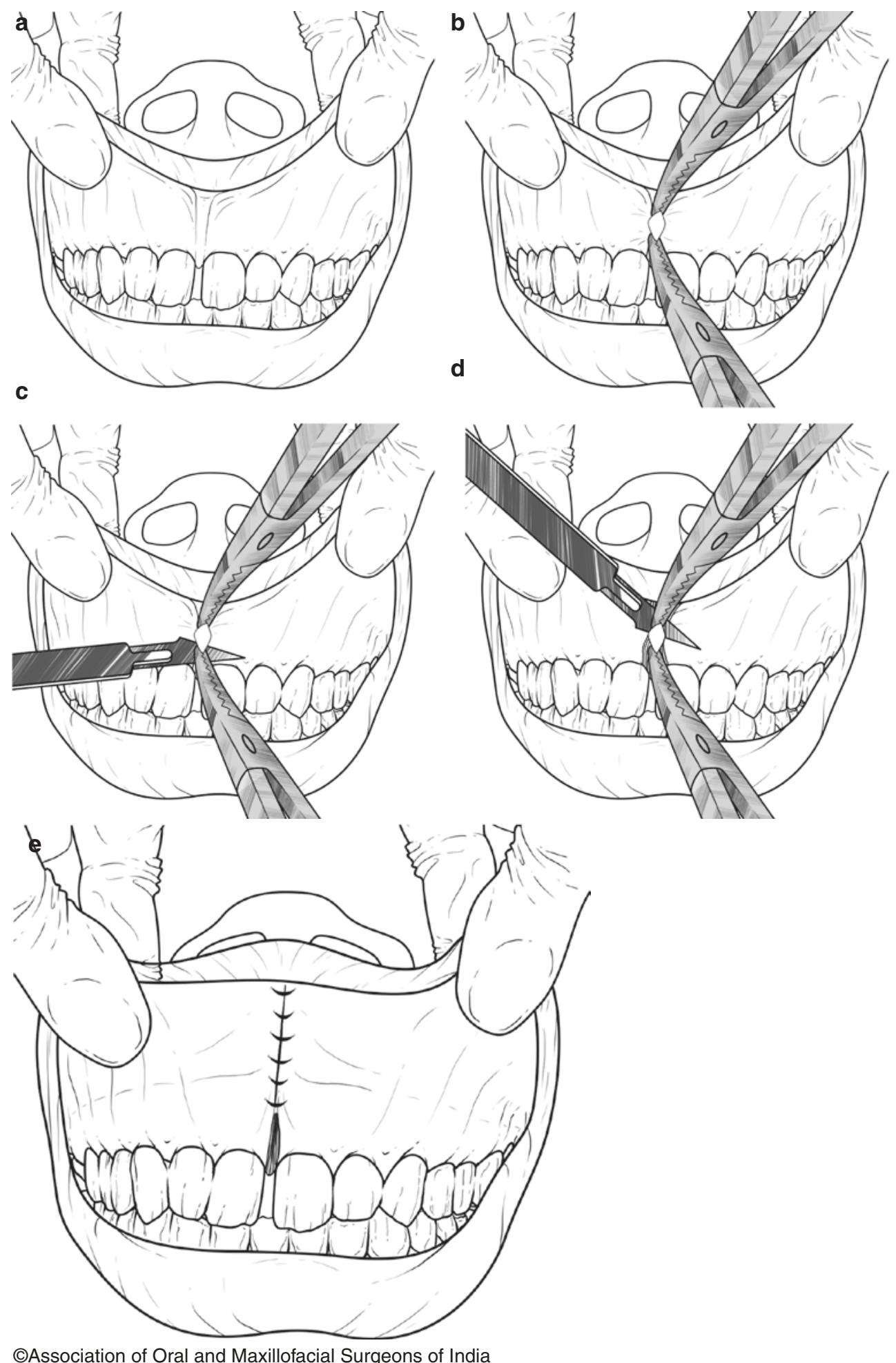

Fig. 17.9 (a) low attached frenum, (b) frenal tissue grasped by forceps, (c and d) diamond-shaped tissue removal, (e) closure

\subsubsection{Lingual Frenectomy (Video 17.2)}

If the frenal attachment is near the crest of the lingual aspect, it will displace the denture. So the need for relief of the high attached frenum is needed. This procedure can be done under local anaesthesia or general anaesthesia (Fig. 17.10ad). When local anaesthesia is used, bilateral lingual nerve block and infiltration are used. The tongue is grasped with traction sutures or forceps and the attachment of frenum to the ridge is cut and the wound is closed with sutures. In 

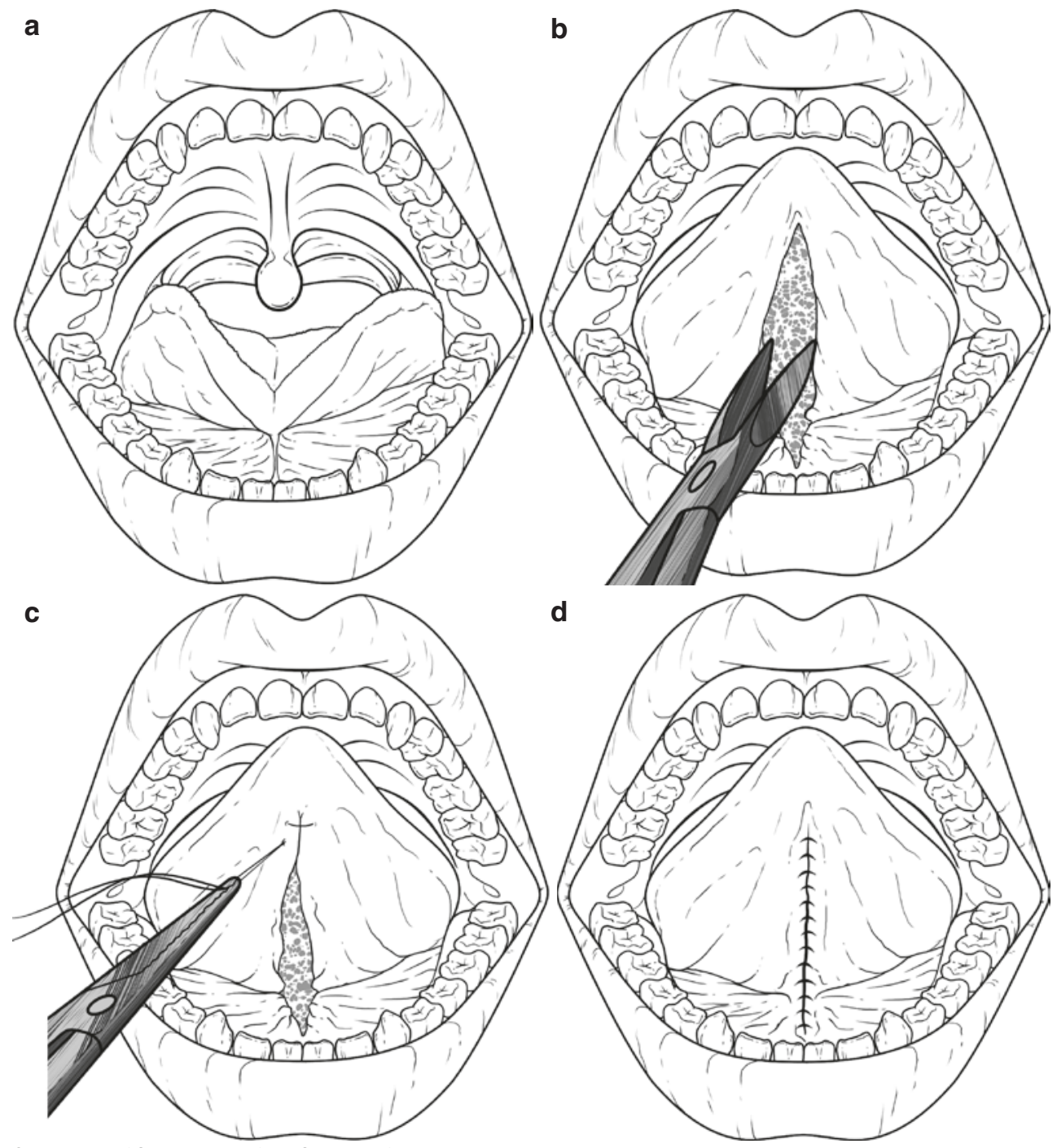

CAssociation of Oral and Maxillofacial Surgeons of India

Fig. 17.10 (a) High attached lingual frenum, (b) excision of frenum, (c and d) closure

some, a more extensive procedure is needed. Here, a transverse incision is made between ventral aspect of tongue and caruncle of submandibular duct. Sectioning of some fibres of the genioglosus muscle may yield greater degree of freedom. Diamond-shaped defect is closed with interrupted sutures. Postoperative pain is managed by analgesics and oedema controlled by steroids. There may be some ecchymosis in the floor of the mouth.

\subsection{Ridge Extension Procedure}

They are defined as the procedures surgically designed to uncover the existing basal bone of the jaw by repositioning the overlying mucosa and muscle attachments to an inferior position in mandible or to a superior position in maxilla. This will enable to accommodate the larger denture flanges, thus contributing to stability and retention (Tables 17.1 and 17.2).

\subsubsection{Vestibuloplasty [Sulcoplasty, Sulcus Extension] (Box 17.4)}

The reduction or obliteration of the sulcus is caused by [1] resorption of the alveolar process, [2] abnormally high muscle attachment in mandible or low on the maxilla, [3] scar tissue resulting from trauma or infection from the contiguous soft tissue.

Vestibuloplasties are carried out in mandible and maxilla. In mandible, both labial and lingual vestibuloplasties are performed. Stability of a denture can be improved by deepening the mandibularsulcus, generating more attached tissues over the functional ridge, and permanently maintaining the 
Table 17.1 Mandibular ridge extension procedures

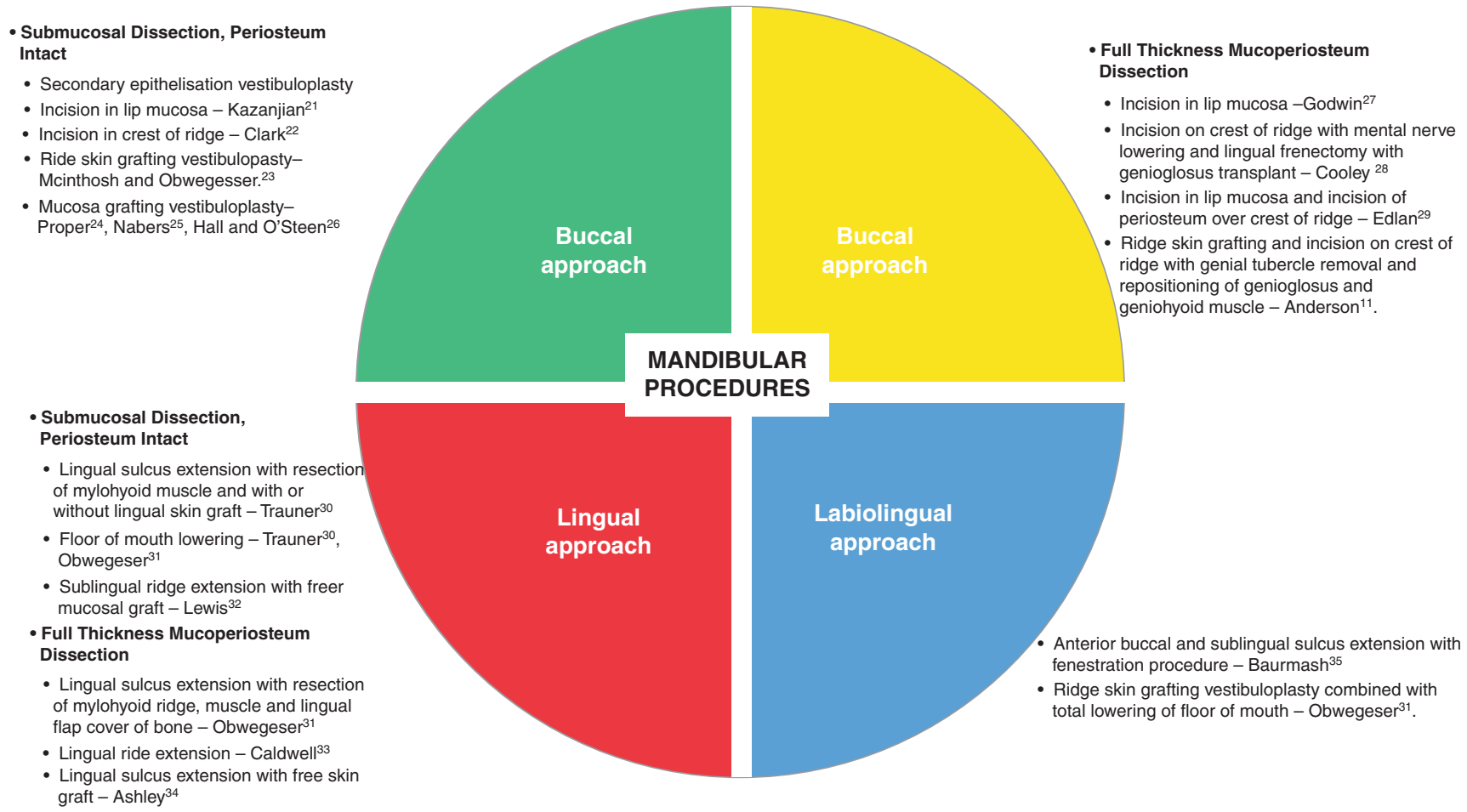

Table 17.2 Maxillary
extension procedures procedure
Buccal approach

1.Secondary epithelization vestibuloplasty

a.Full thickness mucoperiosteal dissection-Collett ${ }^{36}$

b.Submucosal dissection, periosteum intact-Szaba ${ }^{37}$

2.Submucosal vestibuloplasty-Obwegesser ${ }^{31}$, Yrastorza ${ }^{38}$

3.Ridge skin grafting vestibuloplasty-Weise ${ }^{39}$, Schuchardt ${ }^{40}$

4.Buccal sulcus skin grafting-Esser ${ }^{41}$, Gilles $^{42}$

5.Ridge mucosa grafting vestibuloplastyObwegesser ${ }^{31}$,Steinhauser ${ }^{43}$, Maloney and associates ${ }^{44}$ improved vestibular depth. Mandibular vestibuloplasty is carried out to predictably increase and maintain the functional alveolar ridge.

Preoperative preparation of the vestibuloplasty patients includes history, clinical examination, and suitable radiographs. Radiographs, especially orthopantomograph, help to evaluate the ridge height. The commonly performed ones are discussed in this section.

\subsubsection{Transpositional Flap Vestibuloplasty [Lip-Switch Procedure]}

The credit of this procedure goes to Kazanjian [21], later modified by many in the literature. Kethley and Gamble [45] modification finds more acceptance in the literature. The selection criteria for this procedure are the minimum bone height of $15 \mathrm{~mm}$ between the mental foramen areas. 
Box 17.4 Other Historically Relevant Vestibuloplasty Methods

\section{Kazanjian's [21]}

Flap is raised supraperiosteally from the lower lip.

Mobilised to the new vestibule and positioned

Stabilised by stent or dentures

The raw area in the lower lip is allowed to heal by secondary epithelisation

Godwin [27] modification A similar technique, except subperiosteal stripping, was performed

Kethley and Gamble [45] modification of Kazanjian-the lip switch technique A labial mucosal flap is raised and extended to the crest of the ridge from the lip incision placed initially

\section{Clark's [23]}

The facial surface of the ridge is chosen to raise the flap

The dissection in supraperiosteal fashion is done.

The raw area is in the ridge surface Obwegessor [31] modification over the denuded surface to facilitate healing. Tortoerlli [46] modification

Fenestrations are made in the periosteum along the base of the newly created vestibule in a horizontal fashion. The use of skin grafts

\subsubsection{Procedure}

The technique involves the administration of local anaesthesia followed by mucosal incision. The mucosal flap is elevated and pedicled near the crest of the ridge (Fig. 17.11a and b). An incision is placed near the superior portion of the periosteum. A supraperiosteal dissection is carried in the inferior direction, thereby removing the attachments of the muscular and connective tissues to the indicated vestibular depth. The labial periosteal margin is sutured to the incised lip mucosa. This is followed by the suturing of the pedicled flap to the periosteum at the depth of the vestibule.

\subsubsection{Mandibular Vestibuloplasty with Grafting}

Indicated in cases where the lip switch procedure is not possible due to the inadequate tissue availability. The options permissible in such cases were either secondary epithelisation or covering the denuded areas with grafts. The former became less popular because of wound contraction leading to the loss of vestibular depth. Here, the desired alveolar height between the mental foramina is not less than $10 \mathrm{~mm}$ in contrast to the minimum of $15 \mathrm{~mm}$ in lip switch.

\subsubsection{Procedure}

An incision is placed at the mucogingival junction and a supraperiosteal dissection carried out to the desired vestibular depth. During the dissection, care is taken not to dissect more than half of the mentalis muscle to avoid the chance of
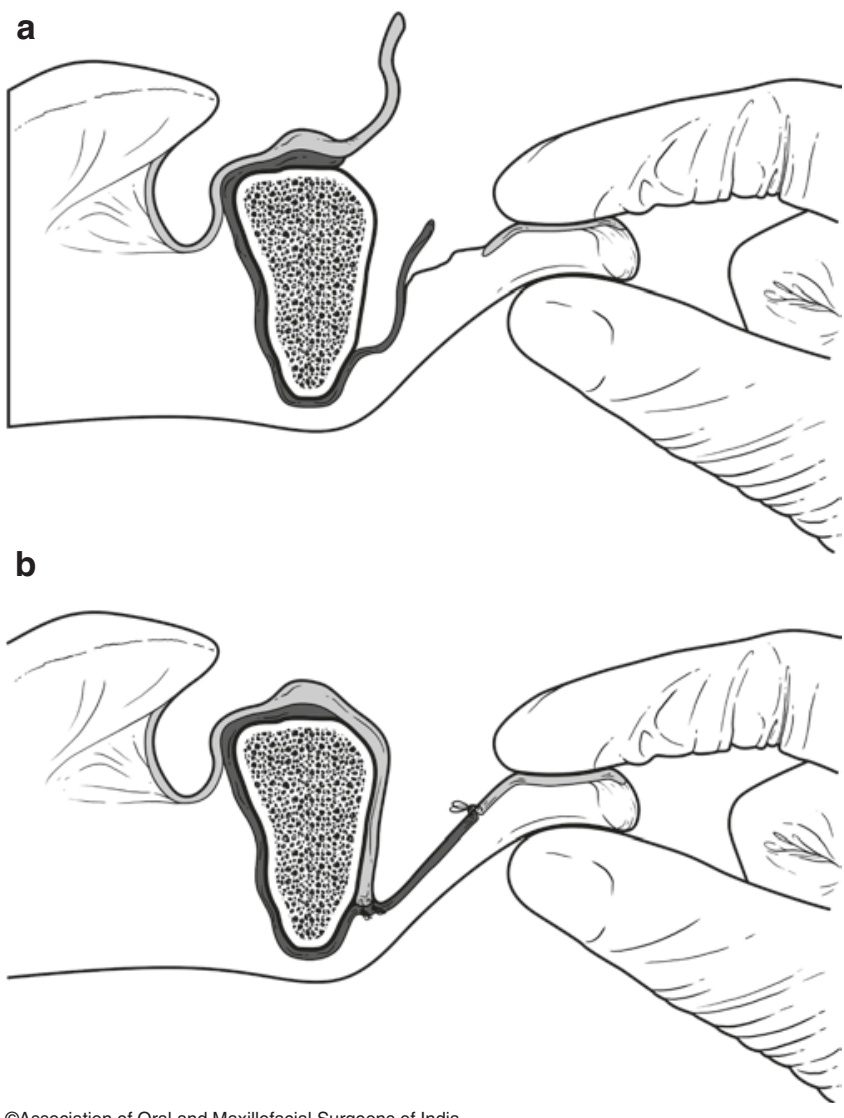

CAssociation of Oral and Maxillofacial Surgeons of India

Fig. 17.11 Lip switch vestibuloplasty (a) Labial mucosa pedicled near the crest of the ridge (b) pedicled flap sutured to the depth of the vestibule

the ptosis of the submental tissues referred as 'witch chin'. The margin of the incision is now sutured to the periosteum in the depths of the vestibule. The harvested graft is now placed over the recipient bed after ensuring adequate haemostasis. The graft is contoured to the correct shape, fenestrated, placed, and fixed on the periosteum with the help of stent or by sutures.

The grafts may be harvested from cutaneous or mucosal areas or allogenic in nature. The best sites for skin graft harvesting are medial thigh or caudal to the iliac crest, where fewer adnexal structures are present in the skin. Areas where smaller grafts are needed, mucosal grafts may be considered, which may be taken from the palate or buccal mucosa. Cultured skin grafts are also becoming popular but lack the mechanical and functional elements of the autogenous grafts. The narration of techniques of grafting is beyond the scope of this chapter.

\subsubsection{Lingual Vestibuloplasty: Anterior Region}

The severe atrophy of the mandible in the anterior region makes the genial tubercles prominent and affects the stability 
of the denture by the attached muscles. The exposure of the tubercles and the detachment of the genial muscles are accomplished by the procedure of lingual vestibuloplasty. Initially proposed by Kazanjian [21] and later modified by Lewis [32], the disadvantage of this procedure may be the loss of tongue function and difficulty in swallowing, which is encountered if more than half of the muscle is removed.

\subsubsection{Procedure}

Incision is made in the anterior aspect of the crest of the alveolar ridge and subperiosteal flap is elevated. Dissection continued till the prominent genial tubercle with the attached muscle is encountered. The genial muscles are separated from the ridge and the tubercle is trimmed with bur and smoothed with bone file. The flap along with the muscle is lowered to the desired depth and it is maintained in the new position by stent and extraoral sutures. The exposed area is allowed for secondary re-epithelisation.

\subsubsection{Lingual Vestibuloplasty: Posterior Region}

If the amount of the resorption is severe that it results in the displacement of the denture by the action of mylohyoid, then lowering of the mylohyoid muscle should be considered. This can be done alone or in combination with labial vestibuloplasty. The amount of the available depth can be assessed by a clinical manoeuvre, by placing a gloved finger along the lingual side of the mandible and asking the patient to touch the palate with the tip of the tongue. If this action displaces the finger, lowering the floor of mouth should be considered.

\section{Trauner's Technique [30]}

Incision is made from the retromolar area to the premolar area of the lingual aspect of the alveolar crest. Mucoperiosteal flap is raised and exposes the mylohyoid and the overlying periosteum. Dissection in the supraperiosteal plane is preferred to avoid the chance of the damage of the lingual nerve. The muscle with the flap is lowered to the desired depth. Sutures are passed through the mylohyoid and mucosa and secured to the skin extraorally. The exposed area is allowed for secondary re-epithelisation (Fig. 17.12a-f).

\subsubsection{Other Variations Include (Box 17.5)}

Brown [47] -incision similar to Trauner's but a full-thickness mucoperiosteal flap is reflected to reveal the mylohyoid ridge. Here, the muscle is detached and the ridge is smoothed. The difference here is the sulcus is not deepened, but the problem with the ridge prominence is solved.

Caldwell [33] - here a crestal incision is employed and a supraperiosteal approach to access the mylohyoid ridge and the attached muscle. The flap is sutured to the original position. The new position is secured by a stent or a modified denture. Instead a polyethylene tubing can be also used to maintain the position.

Edlan [29] - here, a combination of the lip switch vestibuloplasty and lowering the floor of mouth is accomplished. Incision is made in the buccal sulcus instead of the crest of alveolar ridge. Plastic tubes are used to maintain the depth of the sulcus.

Hopkin [48] — mentioned as Hopkin's operation in the literature, it uses the combined modalities like labial vestibuloplasty, submucous sulcoplasty to remove the buccinator insertion and bilateral mylohyoid ridge reduction.

\subsection{Ridge Augmentation Procedures}

In atrophic maxilla, the alveolus may be accentuated by different options; earlier, vestibuloplasty was the choice of procedure. But the results achieved were not long lasting because of the continued resorptive process. So, the advent of augmentation came into action. In severe resorbed and atrophic ridges of Cawood and Howell [6] classes IV-VI, augmentation became mandatory. Unfortunately, this area of preprosthetic surgery has gained little attention, possibly there seemed to be no effective operation for ridge augmentation using an extraoral method; moreover, the penetration into the oral cavity during the procedure was deemed tantamounting to failure, as the surgeons are reluctant to perform the elective augmentation of mandible (Table 17.3).

Classification of alveolar ridge deficiency by Kent et al. [49] acts as a yardstick to identify the ridge nature and the grafting options.

Class 1 -alveolar ridge is adequate in height but inadequate in width, usually with lateral deficiencies or undercut areas. Patient receives hydroxyapatite alone.

Class 2-alveolar ridge is deficient in both height and width and presents a knife-edge appearance. Patient receives hydroxyapatite alone.

Class 3-alveolar ridge has been resorbed to the level of the basilar bone producing a concave form in the posterior areas of mandible and a sharp bony ridge form with bulbous mobile soft tissues in the maxilla. Patient receives hydroxyapatite with or without autogenous cancellous bone.

Class 4-there is resorption of the basilar bone producing pencil-thin flat mandible or maxilla. Patient receives both hydroxyapatite with autogenous bone. 
Fig.17.12 Lingual

vestibuloplasty methods (a)

Normal, (b) Trauner, (c)

Brown, (d) Caldwell, (e)

Hopkins, (f) Edlan
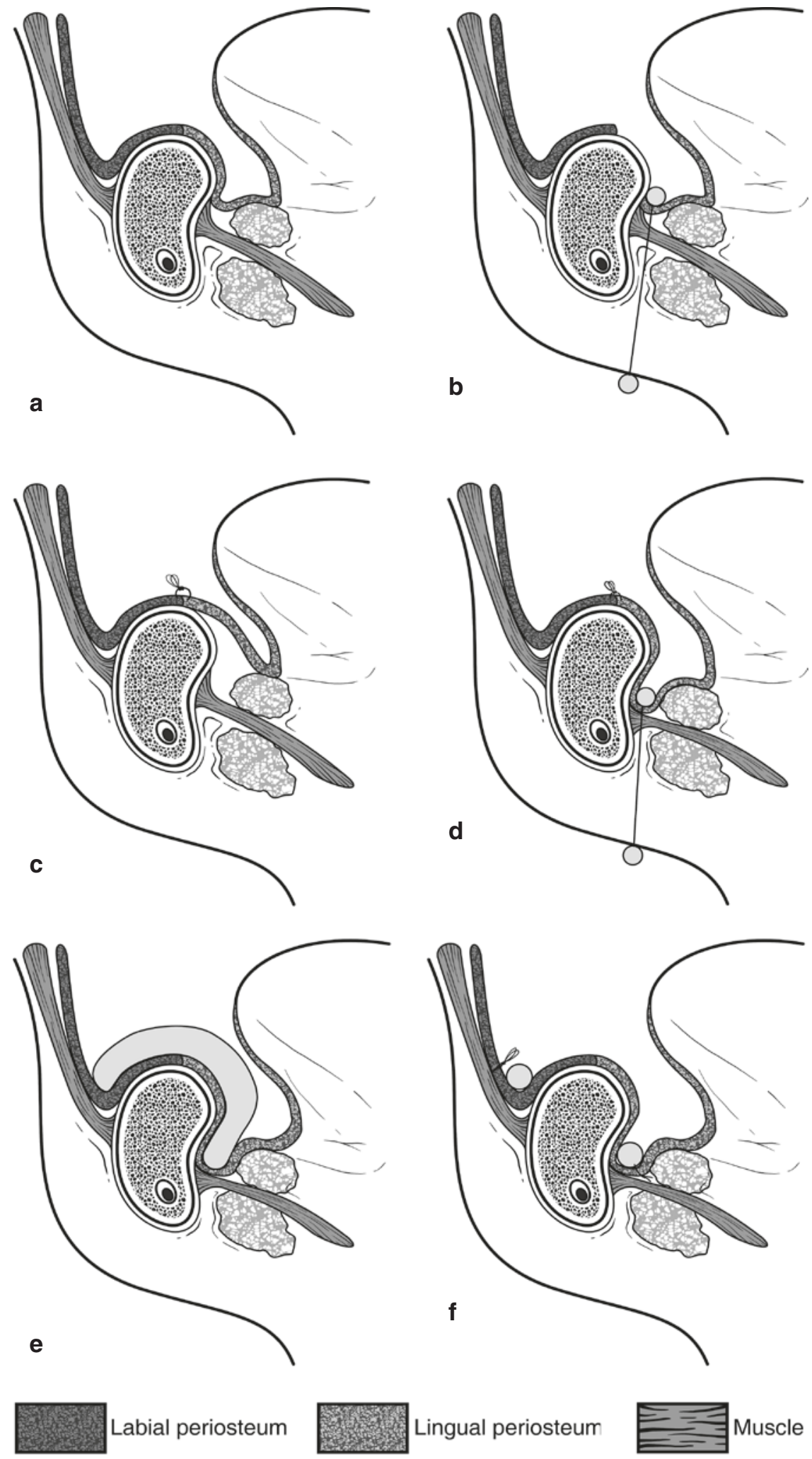
Labial periosteum

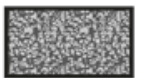

Lingual periosteum

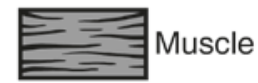




\section{Box 17.5 Lingual Vestibuloplasty Techniques}

Trauner [30]

Carried over the posterior areas from retromolar pad to the premolar region with supraperiosteal dissection

Mylohyoid muscle lowering is performed

\section{Brown [47]}

Full thickness mucoperiosteal flap reflected

Ridge is smoothened after the mylohyoid muscle is released Not used alone but is combined with other vestibuloplasties

\section{Caldwell [33]}

Carried over both posterior and anterior areas

Detachment of mylohyoid and genioglosus muscle is done
Edlan [29]

Combination of lip switch vestibuloplasty with floor of mouth procedure

Table 17.3 Ridge augmentation procedures

Inferior border augmentation

Sinus lift and grafting procedures

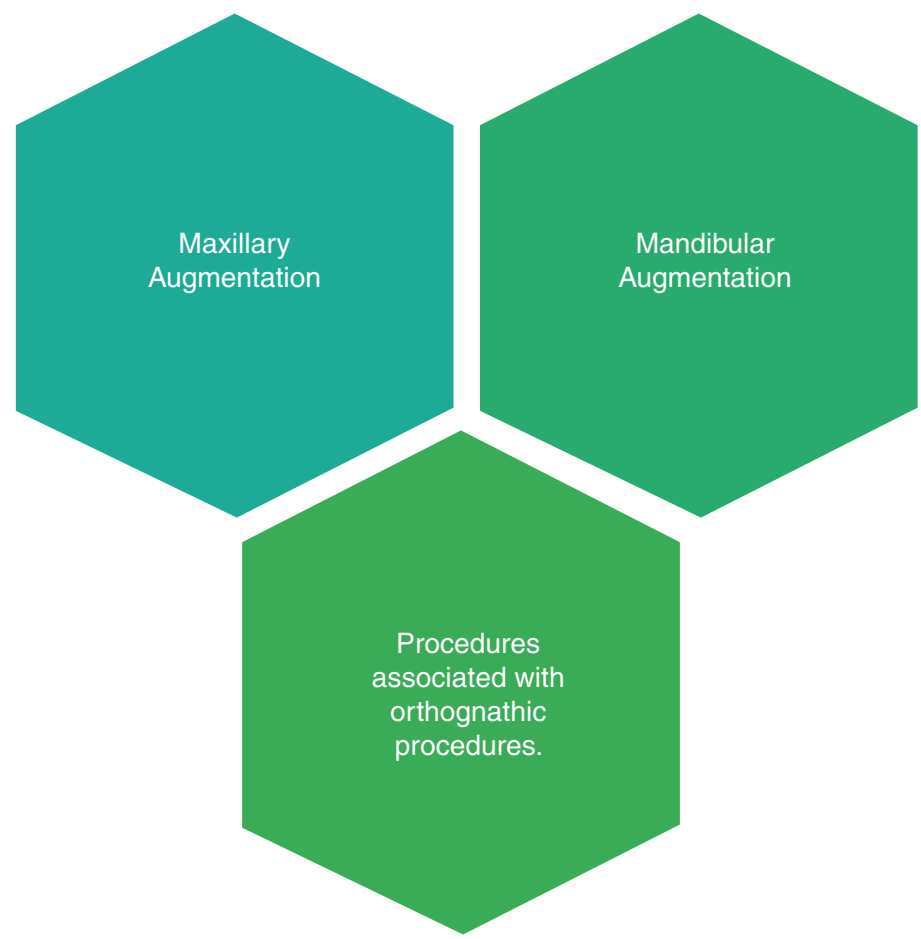

Inferior border augmentation Superior border augmentation Interpositional augmentation Visor ostetomy and modifications
Autogenous bone grafting remains the ideal option to rectify the deficiency but accompanied by disadvantages like the need for hospitalisation and general anaesthesia, donor site morbidity, extensive surgical procedure, professional expertise and patient compliance.

\subsubsection{Inferior Border Augmentation}

The resorption of the mandible has been so extensive that it results in the severely atrophic condition and liable for a pathological fracture. In such a case, augmentation has to be achieved in the inferior border. The procedure was originally proposed by Marx and Sanders [50] and later modified by Quinn [51]. The procedure carries the advantages of nonobliteration of the sulcus, allowing the placement of the interim denture and making the secondary vestibuloplasty easier. But the procedure carries the burden of an extraoral scar and the chance of altering the facial appearance. Access to the lower border is gained by different ways by different authors. Some literature supports the use of incision used in the neck dissection, viz. a supraclavicular incision. It extends from the anterior border of sternocleidomastoid to the opposite counterpart. According to Sanders [50], a continuous submandibular incision from angle to angle is sufficient. Ridley and Mason [52] proposed the use of three small submandibular incisions connected by subperiosteal tunnels. The latter is opposed by Sanders [50] for the high chance of resorption by the pressure on the graft. Dissection is carried out to expose the inferior border of mandible. Two ribs of 15 to $20 \mathrm{~cm}$ long are harvested and bent to adapt the shape. Three or four transosseous holes are drilled in the lower bor- 
der of mandible and wires are passed through these holes. One rib is placed against the lingual aspect and the other abutted against the buccal aspect. The space between the ribs is packed with available cortical chips. Ribs are secured in place by interosseous wires in circumferential pattern. Closure is achieved in layers and pressure dressing is applied. The narration of the technique of graft harvesting is beyond the limit of this chapter.

\subsubsection{Superior Border Augmentation}

The superior border enhancement is needed [53] in cases where the resorption is so severe that the height of the mandible is insufficient to accommodate the prosthesis or in cases where the patient suffers from pain during mastication, secondary to the pressure on the mental neurovascular bundle (Fig. 17.13a and b).

Recipient site is prepared and the mucosa is infiltrated with local anaesthetic solution containing epinephrine to achieve haemostasis. Crestal incision from the retromolar area to the opposite retromolar area is made and mucoperiosteal flap is raised. Care to be taken to avoid the mental nerve if it is near the superior border. Depending on the position, it may be lowered or freed. The existing superior border is exposed and prepared to receive the graft. The lingual flap is reflected to the level of the mylohyoid muscle. Davis and colleagues [54] described the technique of ridge augmentation, which uses two rib grafts of $15 \mathrm{~cm}$. The ribs may be adjacent or alternate. One rib may be contoured by vertical scoring on the inner surface or by bending. Leake [55] recommends splitting the rib longitudinally and then bending it with forceps. The second rib is cut into pieces and packed against the solid rib. Before the placement of the rib, the superior aspect of the mandible is already prepared and suited to receive it. The posterior aspect of the rib should be in contact with mylohyoid shelf, slightly on the lingual aspect of the ramus. The ribs are fixed by three interosseous wires, one placed through each mylohyoid shelf and the other in the anterior region in the midline. Flaps returned to cover the graft.

\subsubsection{Interpositional Grafting}

Concept of placing bone grafts between the osteotomised segments of the mandible was initially proposed by Barros saint and Pasteur [56] and later experimentally proved by Danielson and Nemarich [57]. The horizontal osteotomy is achieved by an incision made inferior to the crest of the ridge. The length of the incision is determined by the area to be augmented. Incision is designed from the retromolar area to the other. A buccolabial mucoperiosteal flap is raised and the flap is greatly undermined to get adequate coverage of the graft. Issues are left untouched to ensure the patency of the vascular supply. The horizontal osteotomy is made by burs and osteotomes, and precise osteotomy is obtained by use of saws. The cut may be placed either above or below the canal, depending on the proximity to the inferior border. Transosseous holes are drilled in the lower and upper segments. The harvested graft is interposed between the osteotomised segments and stabilised by the wires. The flap is returned and approximated with sutures (Fig. 17.13c and Table 17.4).

\subsubsection{The Visor Osteotomy and Modified Visor}

The procedures of vestibuloplasty and floor of the mouth lowering may not be always successful to provide a stable and adequate basis for the prosthesis. The situation of the reduced vertical height needs to get addressed. Harle [58] published a report of an original and promising method to augment the alveolar ridge by means of a pedicled bone
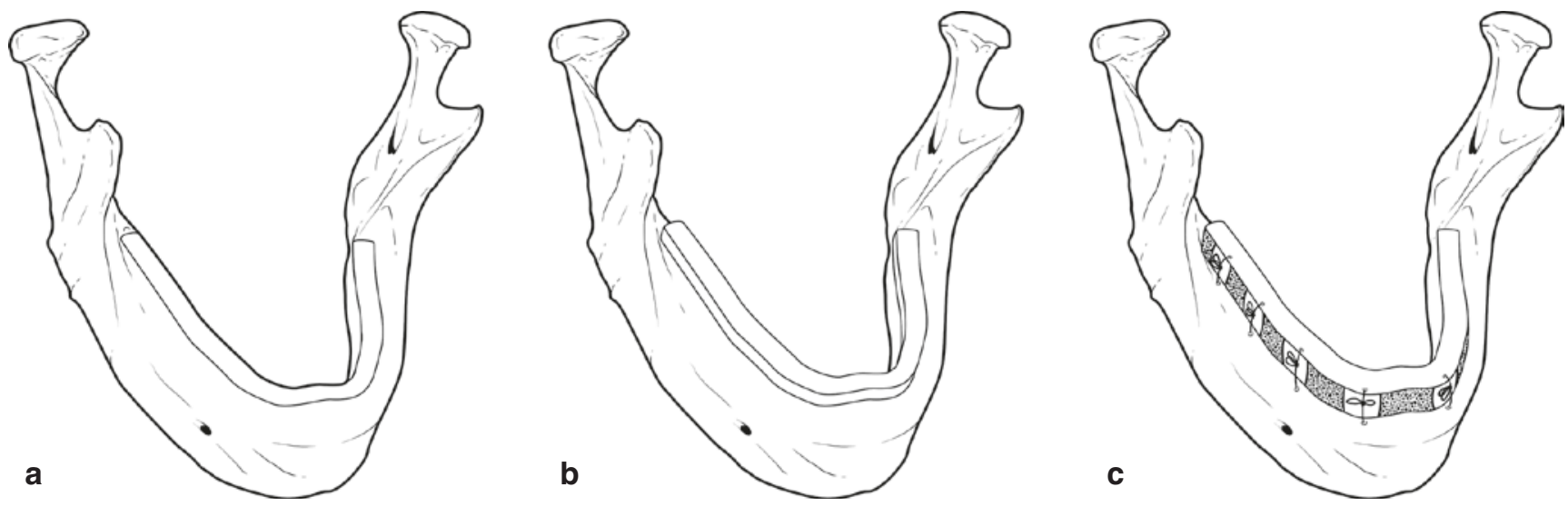

CAssociation of Oral and Maxillofacial Surgeons of India

Fig. 17.13 (a and b) Superior border augmentation, (c) Interpositional grafting 
Table 17.4 Mandibular ridge augmentation procedures

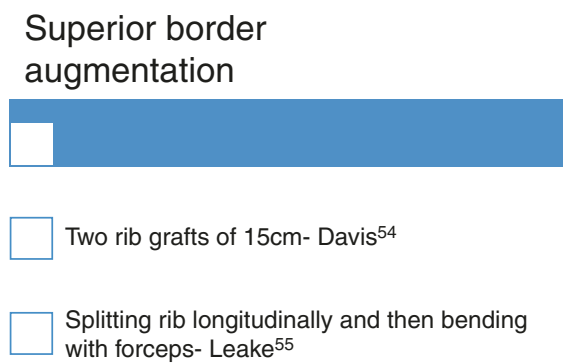

\section{Visor osteotomy}

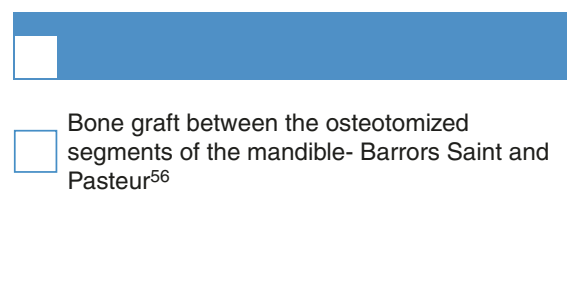

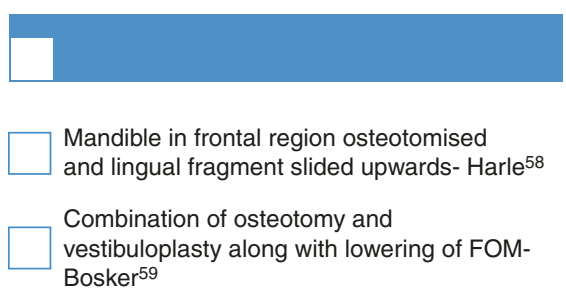

graft. This procedure possesses less danger of infection and rejection of the transplant and of resorption by remodelling processes. The muscles and periosteum in the labial side are reflected and the mandible in the frontal region is osteotomised and split in the length. The mobile lingual fragment is slid upwards, together with the adherent soft tissue, and fixed to the basal part of the mandible by intraosseous and perimandibular wiring. Bosker [59] improved this method by combining the osteotomy and the vestibuloplasty and lowering of the floor of the mouth in a one-stage procedure.

The advantage of this modified technique of Bosker [59] is it needs only single operation and hospitalisation of the patient, the prosthesis can be made in 4-6 weeks sooner, and the operative procedure is simpler.

Sladen and peterson [60] describe the body sagittal osteotomy and raising the lingual cortical portion of the mandible without detaching the lingual soft tissues for the intact vascular pattern. The raised lingual ridge is positioned in the new place, while the buccal counterpart is augmented with cancellous marrow. This procedure is now referred to as visor osteotomy in the literature.

The incision and the mode of raising the mucoperiosteal flap is essentially the same as that used in the horizontal osteotomy as described earlier. Sagittal cut is made between the buccal and lingual cortical plates from the third molar to the opposite third molar area. Precise cutting is achieved by the use of oscillating and reciprocating saws. The lingual segment, which is pedicled to the mylohyoid, digastrics and genial musculature and the soft tissues, is elevated vertically and fixed in the preplanned position with wires through the transosseous holes. The lateral aspect of the elevated segment may be filled with the cancellous bone to compensate the height deficiency created by the vertical repositioning. The flap is returned and wound is closed by sutures.

\subsubsection{Graft Materials}

Iliac bone crest and rib have traditionally been applied to augment the jaws. Boyne [61] suggested a bone regeneration method, which employs a vitalium mesh tray containing haematopoietic bone marrow encased in a nylon-reinforced
Millipore filter. The filter prevents the connective tissue elements accessing the defect and thereby enhances the osseous regeneration. The concern regarding the graft material is the resorption shrinkage in the future. Many attempts are done by surgeons to minimise the resorption shrinkage of the grafted bone. Danielson and Nemarich [57] advocated the subcortical insertion of bone graft. Farell [62] and associates went ahead with interpositional bone graft with simultaneous vestibuloplasty. Sanders and Cox [50] proposed the use of inferior border rib grafting for augmentation. Notched rib can be contoured to the arc of the mandible, but $50 \%$ loss by shrinkage is a great disadvantage with rib. The literature suggests the use of pure cancellous iliac graft, iliac corticalcancellous sectional grafts with appropriate immobilisation showing excellent healing even in the event of occasional incision dehiscence.

\subsubsection{Augmentation with Synthetic Graft Materials}

A myriad of materials is used for the augmentation of the atrophied ridge. It consists of resorbable and nonresorbable materials. The former finds its application in periodontal pockets, while the latter is extensively used in the management of alveolar atrophy. Hydroxyapatite, a calcium phosphate material with physical and chemical attributes, is nearly similar to dental enamel and cortical bone has been successfully using for decades. Studies by Kent et al. [49] and Drobeck et al. [63] illustrate the usage. Kent et al. [49] used hydroxyapatite in combination with corticocancellous autogenous bone for augmentation. This combination provides additional strength to the mandible as advised by Jarcho et al. [64]. Though block forms are used by Frame and Brady [65], the granular forms also get used in the augmentation process as guided by Kent et al. [51]. When anterior mandible needs augmentation, a single midline vertical incision is used, while for the complete augmentation of mandible, bilateral vertical incisions anterior to mental foramen are used. A subperiosteal tunnel is formed, which can be assessed by a dental mirror and the syringe loaded with graft material is inserted 
through the tunnel and delivered in place. After the tunnel is filled with graft material, the incision is closed with interrupted or horizontal sutures.

In maxilla, a single vertical incision in midline may be sufficient, but in many cases bilateral incisions in the canine regions may accommodate more amount of graft material. It is similar to the procedure in mandible except for the palatal dissection, where the ridge width is needed. Denture can be placed at about 1 month in cases where augmentation is carried out by hydroxyapatite alone or $6-8$ weeks in which both hydroxyapatite and bone are used together. If vestibuloplasty is planned, Kent [49] advocated a waiting period of 8 weeks after graft placement.

\subsection{Conclusion}

The art of designing the soft- and hard-tissue framework for the smooth placement of the prosthesis is a challenging task. This task is achieved by the meticulous planning and execution of the planned presurgical procedures in a systematic manner. The intimidating impressive trends of implantology might have downsized the charm of preprosthetic surgery, yet in certain avenues the preprosthetic surgical manoeuvres become inevitable. The magnitude of vestibuloplasty and ridge augmentation procedures associated with the anticipated patient discomfort should not demote the benefits of preprosthetic surgery in deserving patients, where they suffer from pain or embarrassment by a juggling ill-fitting denture. Such corrections may alter their present situations and successful denture wearing is ensured. So it is not possible to completely thwart or baffle the procedures belonging to the preprosthetic surgery as an obsolete one.

Acknowledgments Fig. 17.6 - Suvy Manuel.

\section{References}

1. Willard AT. Preparing the mouth for full sets of artificial teeth. Dent News Letter. 1853;6:238.

2. Beers WG. Notes from practice. Mo Dent J. 1876;8:294.

3. Roux W. Der Kampf der Teile im Organismus. Ein Beitrag zur Vervollständigung der mechanischen Zweckmässigkeitslehre. Leipzig: Verlag von Wilhelm Engelmann; 1881.

4. Wolff J. Das Gesetz der Transformation der Knochen. Berlin: August Hirschwald; 1892.

5. Mercier P. Residual alveolar ridge atrophy: classification and influence of facial morphology. J Prosthet Dent. 1979;8:24.

6. Cawood JI, Howell RA. A classification of the edentulous jaws. Int J Oral Maxillofac Surg. 1988;17:232-5.

7. Storer R. A radiographic survey of edentulous mouth. Br Dent J. 1957;102:344.

8. Crandell CE, Trueblood SN. Roentgenographic findings in edentulous areas. Oral Surg Oral Med Oral Pathol. 1960;13:1343.
9. Lekholm U, Zarb GA, Albrektsson T. Patient selection and preparation in Per-Ingvar Branemark et al Tissue-Integrated Prostheses. Chicago: Quintessence; 1985. p. 199-209.

10. Dean OT. Surgery for the denture patient. J Am Dent Assoc. 1936;23:2124.

11. Anderson JO. Intra oral skin grafts-an aid to alveolar ridge extension. J Oral Surg. 1969;27:427.

12. Guernsey L. Preprosthetic surgery. In: Kruger GO, editor. Oral and maxillofacial surgery. 6th ed. St. Louis: C V Mosby.

13. Godlee RJ. The torus palatinus. Proc R Soc Med. 1909;2:175.

14. García García AS, Martínez González JM, GómezFont R. Current status of the torus palatines and torus mandibularis. Med Oral Patol Oral Cir Bucal. 2010;15:e353.

15. Moraes Junior EF, Damante CA, Araujo SR. Torus palatinus: a graft option for alveolar ridge reconstruction. Int J Periodontics Restorative Dent. 2010;30:283.

16. Hassan KS, Alagl AS, Abdel H. A Torus mandibularis bone chips combinedwith platelet rich plasma gel for treatment of intrabony osseous defects: clinical andradiographic evaluation. Int J Oral Maxillofac Surg. 2012;41:1519.

17. Kolas S, Halperin V, Jefferis K, Huddleston S, Robinson HB. The occurrence of torus palatinus and torus mandibularis in 2478 dental patients. Oral Surg Oral Med Oral Pathol. 1953;6:44.

18. Kalaignan P, Mohan JS, Jayakumar A. Determination of grading for maxillary and mandibular Tori- an in vivo study. Biomed Pharmacol J. June 2018;11(2):679-88.

19. Haugen LK. Palatine and mandibular tori: a morphologic study in the current Norwegian population. Acta Odontol Scand. 1992;50:65.

20. Reichart PA, Neuhaus F, Sookasem M. Prevalence of torus Palatinus and torus mandibularis in Germans and Thai. Community Dent Oral Epidemiol. 1988;16:61-4.

21. Kazanjian VH. Surgery as an aid to more efficient service with prosthetic dentures. JADA. 1935;22:566-81.

22. Clark HB Jr. Deepening the labial sulcus by mucosal flap advancement: report of a case. J Oral Surg. 1953;11:165.

23. Mcinthosh RB, Obwegeser H. Preprosthetic surgery: a scheme for its effective employment. J Oral Surg. 1969;27:427.

24. Propper RH. Simplified ridge extension using free mucosal grafts. J Oral Surg. 1964;22:469.

25. Nabers JM. Free gingival grafts. Periodontics. 1966;4:243.

26. Hall RD, Steen O. Free grafts of palatal mucosa in mandibular vestibuloplasty. J Oral Surg. 1970;28:565.

27. Godwin JG. Submucous surgery for better denture service. J Am Dent Assocn. 1947;34:678.

28. Cooley DO. Method of deepening maxillary and mandibular sulci to correct deficient edentulous ridges. J Oral Surg. 1952;10:27.

29. Edlan A, Mejchar B. Plastic surgery of the vestibulum inperiodontal therapy. Int Dent J. 1963;13:593.

30. Trauner R. Alveoplasty with ridge extensions on the lingual side of the lower jaw to solve the problem of a lower dental prosthesis. Oral Surg. 1952;5:340.

31. Obwegeser H. Surgical preparation of the maxilla for the prosthesis. J Oral Surg. 1964;22:127.

32. Lewis ET. Surgical correction to the sublingual region. J Am Dent Assoc. 1963;67:364.

33. Caldwell J. Lingual ridge extension. J Oral Surg. 1955;13:287.

34. Ashley FN, Schwartz AN, Dryden MF. A modified technique for creating a lower lingual sulcus. Plast Reconstr Surg. 1953;22:204.

35. Baurmash H, Mandel L, Strelioff M. Mandibular sulcus extension a new technique:preliminary report. J Oral Surg. 1962;20:390.

36. Collett HA. Immediate maxillary ridge extension. Dent Dig. 1954;60:104.

37. Szaba, Garner, Rumpel. Surgical preparation of the maxilla for prosthesis. J Oral Surg. 1964;22:127. 
38. Yrastorza JA. Mandibular sulcus deepening: a modified technique. J Am Dent Assoc. 1963;67:859.

39. Weiser R. Ein Fall von ankylose, verlust des alveolar forsatzes under. Zahnheilk. 1918;34:147.

40. Schuchardt K. Die epidermis transplantation bie der mund vorhofplastik. Dtsch Zahnarztl Z. 1952;7:364.

41. Esser JF. Studies in plastic surgery of the face. Ann Surg. 1917;65:297.

42. Gillies HD, Millard DR. Principles and art of the plastic surgery. Boston: Little Brown; 1957.

43. Steinhäuser EW. Vestibuloplasty- skin grafts. J Oral Surg. 1971;29:777-85.

44. Maloney PL. Mucosal grafts in oral reconstructive surgery. J Oral Surg. 1974;32:705.

45. Ketheley J, Gamble J. The lipswitch - a modification of Kazanjian's labial vestibuloplasty. J Oral Surg. 1978;36:705.

46. Tortoerelli AF. A technique for vestibular sulcus extension. J Prosthet Dent. 1968;20(1):14-20.

47. Brown LJ. A surgical solution to a lower denture problem. Br Dent J. 1953;95:215.

48. Hopkins R, Staford GD. Pre prosthetic surgery of the edentulous mandible. Br Dent J. 1980;148(7):183-8.

49. Kent JN, et al. Alveolar ridge augmentation using nonresorbable hydroxylapatite with or without autogenous cancellous bone. J Oral Maxillofac Surg. 1983;41:629.

50. Sanders B, Cox R. Inferior border rib grafting for augmentation of the atrophic edentulous mandible. J Oral Surg. 1976;34:897.

51. Kent JN, Quinn JH. Correction of alveolar ridge deficiencies with nonresorbable hydroxylapatite. J Am Dent Assoc. 1982;105:993.

52. Ridley MT, Manson KG. Resorption of rib graft to inferior border of mandible. J Oral Surg. 1978;36:46.

53. Blackstone $\mathrm{CH}$, Parker ML. Rebuilding the resorbed alveolar ridge. J Oral Surg. 1956;14:45.
54. Davis WH. Rib graft augmentation to the superior border of the mandible. In: Preprosthetic oral and maxillofacial surgery. Saint Louis: C V Mosby; 1980.

55. Leake D. Contouring split ribs for the correction of severe mandibular atrophy. J Oral Surg. 1976;34:940.

56. Barros saint- pasteure: plastia reconstructive del rebord alveolar: neustra investigacion clinicoquirugica. Acta Odont Venez 1970;8:168.

57. Danielson PA, Nemarich AN. Subcortical bone grafting for ridge augmentation. J Oral Surg. 1976;34:887.

58. Harle F. Visor osteotomy to increase the absolute height of the atrophied mandible- a preliminary report. J Maxillofac Surg. 1975;3:257.

59. Bosker, et al. Visor osteotomy and vestibuloplasty - A one-stage procedure. Int J Oral Surg. 1977;6:127-30.

60. Slade E. Text book of maxillofacial surgery. In: Kruger GO, editor. Personal communication. 6th ed. Saint Louis: C V Mosby; 1977, July.

61. Boyne PJ. Restoration of the alveolar ridge by intramandibular transposition osseous grafting. J Oral Surg. 1968;26:569.

62. Farrell CD. One stage interpositional bone grafting and vestibuloplasty of the atrophic maxilla. J Oral Surg. 1976;34:901.

63. Drobeck HP, et al. Histologic observation of soft tissue responses to implanted, multifaceted particle and discs of hydroxylapatite. J Oral Maxillofac Surg. 1984;42:143.

64. Jarcho M, et al. Hydroxylapaptite synthesis and characterization in polycrystalline form. J Mater Sci. 1976;11:2027.

65. Frame JW, Brady CH. Augmentation of an atrophic edentulous mandible by interpositional grafting with hydroxylapatite. J Oral Maxillofac Surg. 1984;42:89.

Open Access This chapter is licensed under the terms of the Creative Commons Attribution 4.0 International License (http://creativecommons. org/licenses/by/4.0/), which permits use, sharing, adaptation, distribution and reproduction in any medium or format, as long as you give appropriate credit to the original author(s) and the source, provide a link to the Creative Commons license and indicate if changes were made.

The images or other third party material in this chapter are included in the chapter's Creative Commons license, unless indicated otherwise in a credit line to the material. If material is not included in the chapter's Creative Commons license and your intended use is not permitted by statutory regulation or exceeds the permitted use, you will need to obtain permission directly from the copyright holder. 